\title{
Relative Linkages of Stream Dissolved Oxygen with the Environmental Drivers across the Gulf Coast of U.S.A
}

\author{
Aron Gebreslase
}

Follow this and additional works at: https://researchrepository.wvu.edu/etd

\section{Recommended Citation}

Gebreslase, Aron, "Relative Linkages of Stream Dissolved Oxygen with the Environmental Drivers across the Gulf Coast of U.S.A" (2017). Graduate Theses, Dissertations, and Problem Reports. 5655.

https://researchrepository.wvu.edu/etd/5655

This Thesis is protected by copyright and/or related rights. It has been brought to you by the The Research Repository @ WVU with permission from the rights-holder(s). You are free to use this Thesis in any way that is permitted by the copyright and related rights legislation that applies to your use. For other uses you must obtain permission from the rights-holder(s) directly, unless additional rights are indicated by a Creative Commons license in the record and/ or on the work itself. This Thesis has been accepted for inclusion in WVU Graduate Theses, Dissertations, and Problem Reports collection by an authorized administrator of The Research Repository @ WVU. For more information, please contact researchrepository@mail.wvu.edu. 


\title{
Relative Linkages of Stream Dissolved Oxygen with the Environmental Drivers across the Gulf Coast of U.S.A.
}

\author{
Aron Gebreslase
}

Thesis Submitted

to the Benjamin M. Statler College of Engineering and Mineral Resources at West Virginia University

in partial fulfillment of the requirements for the degree of

Master of Science in

Civil Engineering

Omar I. Abdul-Aziz, Ph.D., Chair

Kakan Dey, Ph.D.

P.V. Vijay, Ph.D, P.E.

Department of Civil and Environmental Engineering

Morgantown, West Virginia

2017

Keywords: Data analytics, coastal streams, relative linkages, dissolved oxygen, environmental regimes, Gulf coast, United States. 


\title{
Abstract \\ Relative Linkages of Stream Dissolved Oxygen with the Environmental Drivers across the Gulf Coast of U.S.A.
}

\begin{abstract}
Aron Gebreslase
Dynamics of coastal stream water quality and ecosystem health is influenced by a multitude of interacting environmental drivers. A systematic data analytics approach was employed to determine the relative environmental controls on stream dissolved oxygen (DO) dynamics across the Gulf Coast of U.S.A. Pearson's correlation, principal component, and factor analyses were utilized to examine the interrelations among DO, solar radiation, water temperature, atmospheric pressure, flow rate, nutrients, $\mathrm{pH}$, and specific conductance (a surrogate of salinity) in 36 streams. Relative linkages of DO and the environmental drivers were then reliably estimated by resolving multicollinearity with power-law based partial least squares regression (Nash-Sutcliffe efficiency $=0.58-0.94)$. Based on the dominant controls of DO, streams were grouped into three regions across the U.S. Gulf Coast. In the northern part of Gulf Coast states (Texas, Louisiana, Mississippi, Alabama, and West Florida), water temperatures had the strongest and dictated control on stream DO. However, in the southern part of Texas and Florida coasts, $\mathrm{pH}$ showed the most dominant control on stream DO. Further, streams in between these two regions demonstrated notable controls of multiple drivers (water temperature, stream flow, and specific conductance) on DO. Four dynamic process components adequately described the system data variance in all three regions along the Gulf Coast. For example, the 'climate component' (temperature, solar radiation) in the northern part of Gulf Coast showed 2.7, 3.1, and 3.6 times stronger linkages with stream DO than that of the redox ( $\mathrm{pH}$, specific conductance), nutrient (total nitrogen, total phosphorus), and hydro-atmospheric (flow rate, atmospheric pressure) components, respectively. In contrast, in the southern part of Gulf Coast region, the redox components showed 1.6, 2.3, and 2.6 times stronger linkages with stream DO than that of the climate, nutrient, and hydro-atmospheric components, respectively. The identified environmental regimes and estimated linkages of stream DO provide important information into the dominant drivers and dynamic process components of water quality in urban/natural streams across the U.S. Gulf Coast. The knowledge and insights would help coastal managers and stakeholders to achieve a good stream water quality and ecosystem health.
\end{abstract}




\section{ACKNOWLEGEMENTS}

First, I would like to thank ALMIGHTY GOD for giving me the audacity and sanctioning me with the confidence to fulfill this daunting task. I am indubitably grateful to my Committee Chairman, Dr. Omar I. Abdul-Aziz, for his excellent guidance, caring, and patience; for providing me with an excellent atmosphere for completing this master's thesis; and for soliciting additional resources throughout my master's Science in Civil Engineering (MSCE) Program endeavor. I benefitted from his provocative thoughts and discussion. He provided his perceptive comments and/or constructive feedback in near real-time. This work would have not been possible without his inspirational guidance, enthusiasm, encourangement, and help. My deepest appreciation and a profound thankful note also goes to Shakil Ahmed (Ph.D. Student) and Dr. Khandker Ishtiaq for thier strenuous effort, valuable guidance, and discussion and all Ecological and Water Resources Enginnering Lab (EWREL) members 2017. Although it is impossible to list everyone to whom I am indebted, several persons deserve special mention. my committee members, Dr. Kakan Dey and Dr. P.V. Vijay, for accepting to serve and their support.

Finally, I would like to acknowledge with gratitude, the support and love of my family- my parents, Kidane Gebresilase and Tsehaynesh Woldegerghish, my brothers, Mebrahtu, Dawit, Mehari, Dr. Semere, Robel, and Deacon Kibrom and my sisters Milashu, Nazret, and Elsa for their constant support and encouragement. They all kept me going, and this thesis would not have been possible without them. 


\section{TABLE OF CONTENTS}

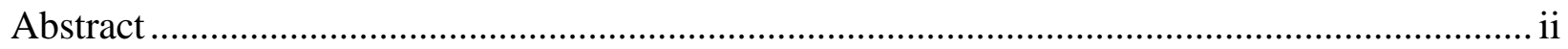

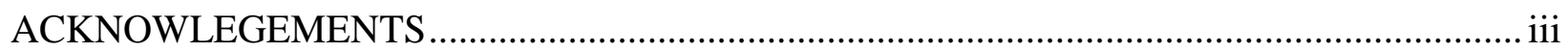

TABLE OF CONTENTS ................................................................................................... iv

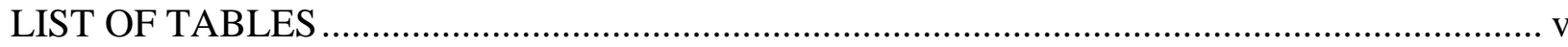

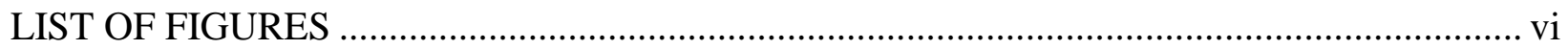

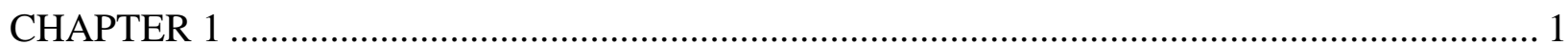

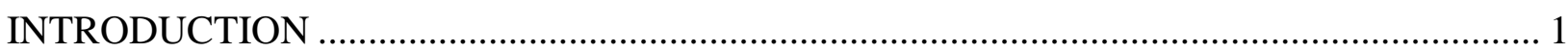

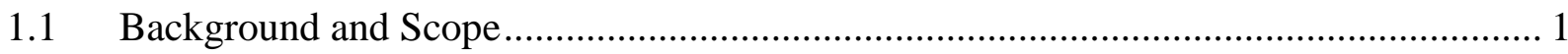

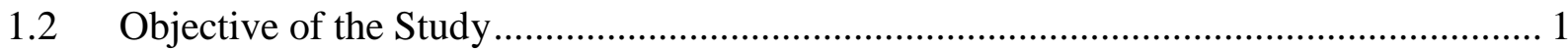

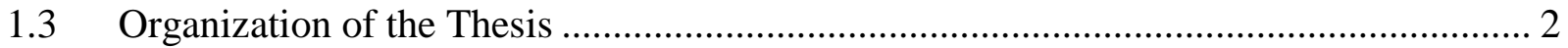

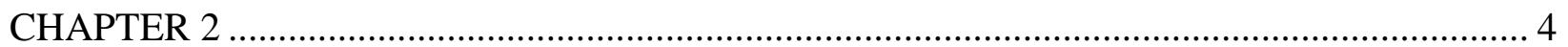

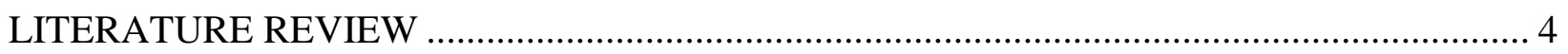

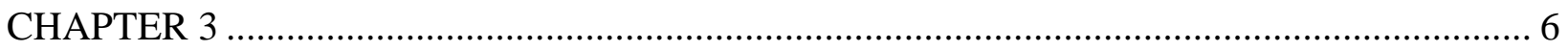

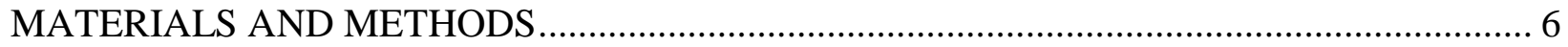

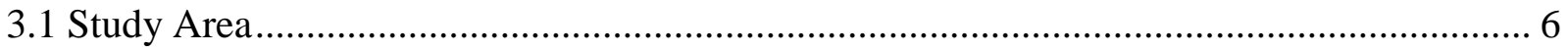

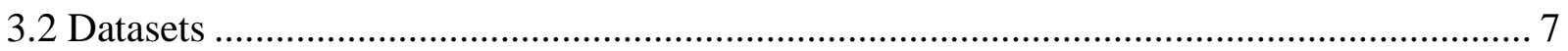

3.3 The Data Analytics Framework ……………………….............................................. 10

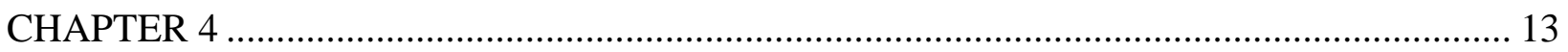

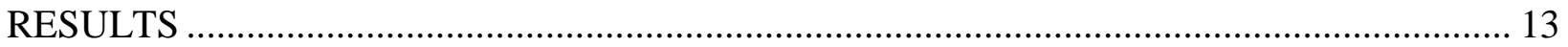

4.1 Mutual Correspondences of the Dynamic Environmental Drivers .................................... 13

4.2 Relative Orientations and Interrelations of Stream DO with the Dynamic Environmental

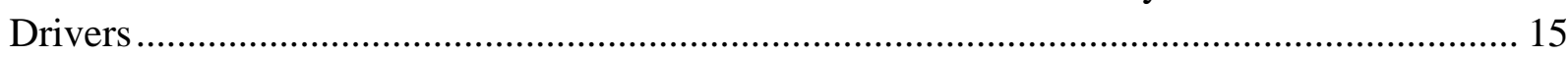

4.3 Major Water Quality Drivers Based on Independent Latent Factors................................. 18

4.4 Estimation of the Relative Linkages of Stream DO with the Predictors............................. 20

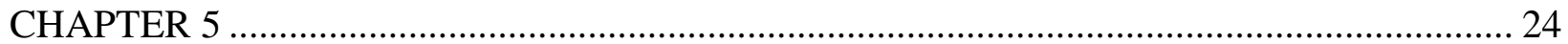

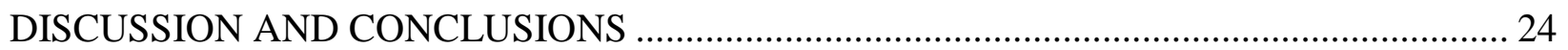

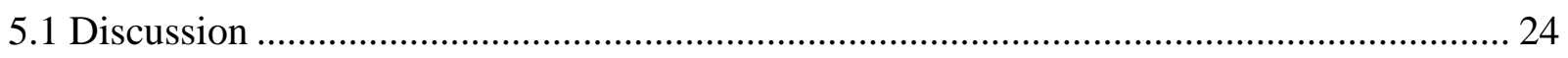

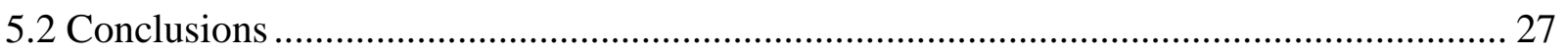

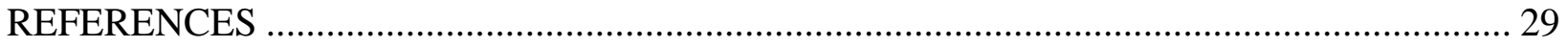

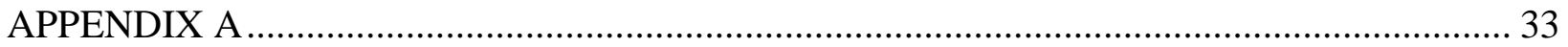




\section{LIST OF TABLES}

Table 1: Ensemble mean and standard deviations (in parenthesis) of the observed stream DO and the dynamic environmental drivers across the the Gulf Coast of U.S.A. ................................ 8

Table 2: Ensemble mean Pearson correlation coefficients (r) of dissolved oxygen with dynamic environmental drivers of the three regions.

Table 3: Representative factors with their optimized loading on stream DO and corresponding dynamic environmental drivers of the identified three regions.

Table 4: Ensemble mean and standard deviation (in parenthesis) of the beta linkages after 1000 Monte Carlo simulations for the identified regions.

Table 5: Aggregated relative linkages of the process components for the four regimes after 1000 Monte Carlo simulation with mean and standard deviation (in parenthesis). 


\section{LIST OF FIGURES}

Figure 1: Study area, Coastal watershed, and the location of water quality monitoring stations. . 6

Figure 2: The data analytics framework to determine the relative linkages of stream dissolved oxygen with the dynamic environmental drivers................................................................ 11

Figure 3: Representative biplots of the three regions obtained from principal component analysis, showing the interrelations of dissolved oxygen with dynamic environmental drivers: (a) TW dominated regime, (b) Q dominated regime, (c) SC dominated regime, and (d) $\mathrm{pH}$ dominated regime. 17

Figure 4: Plot of cross-validated (a) normalized AIC, (b) Eigenvalue, and (c) Nash-Sutcliffe efficiency (NSE) with the number of incorporated partial least square components of all stations. 


\section{CHAPTER 1}

\section{INTRODUCTION}

\subsection{Background and Scope}

Clean water is important in supporting a healthy stream ecosystem. Dissolved oxygen (DO) is a general indicator of stream water quality. Stream water quality is shaped by various interacting and dynamic environmental drivers in relation to climate, hydrology, and land use/cover. However, existing literature lacks large-scale data analytics and modeling investigations of stream water quality in relation to the dynamic environmental drivers, particularly in the context of urbannatural watersheds of U.S. Gulf coast representing a large geographical and longitudinal gradient. Stream water quality in the coastal environment of the Gulf of Mexico has been deteriorating rapidly by anthropogenic activities (Bricker et al., 2008). Rabalais et al. (1996) reported that human activity had increased the discharging of nutrient loading in the Gulf Coast. Previous studies of coastal stream water quality along the Gulf coast are mostly limited to the Mississippi River delta. Moreover, the previous studies focused only on the linkages of stream water quality with the land use activities (Basnyat et al. 1999). Further, existing studies often used regressionbased modeling approaches to estimate the links of stream water quality with land uses without resolution of multicollinearity (mutual correlations) among the interacting drivers. Understanding and estimation of the relative linkages of stream DO with the dynamic environmental drivers by resolving multicollinearity can provide insights into the stream water quality dynamics, and help coastal managers to achieve clean water in the Gulf Coast and similar regions around the world.

\subsection{Objective of the Study}

The overall goal of this study is to determine the dominant environmental controls of stream DO dynamics across the Gulf Coast. The research involves processing and analyses of observed data 
for DO, solar radiation, water temperature, atmospheric pressure, flow rate, nutrients, $\mathrm{pH}$, and specific conductance (a surrogate of salinity) in 36 streams. The water quality data were gathered from the U.S. Geological Survey and the U.S. Environmental Protection Agency. Hourly climatic variables were obtained from the National Solar Radiation Data Base (NSRDB). The study employed systematic data analytic approach sequentially: Pearson's correlation matrix, principal component analysis (PCA), factor analysis (FA), and partial least squares regression (PLSR) to corroborate findings and reliably estimate the dominant controls of stream DO.

The specific research objectives of the study are as follows:

- Obtain and process long-term observations of stream water quality and dynamic environmental drivers along the Gulf Coast.

- Employ Pearson's correlation, principal component analysis, and factor analysis to examine the interrelations among DO and the dynamic environmental variables.

- $\quad$ Estimate the relative linkages of DO with the dynamic environmental drivers using powerlaw based partial least squares regression.

The research findings are expected to provide new information and insights into the dominant drivers and dynamic process components of stream DO. The knowledge would help coastal managers to achieve a healthy stream ecosystem along the U.S. Gulf Coast and around the world.

\subsection{Organization of the Thesis}

This thesis is comprised of four distinct chapters. The current chapter provides a brief introduction and scope along with the objectives and organization of the thesis. Chapter 2 describes the study area, data preparation for water quality and environmental variables, and detailed methodology 
used for the research. Chapter 3 describes the results obtained from four systematic data analytics approach. Chapter 4 consists of a discussion of results and conclusion. 


\section{CHAPTER 2}

\section{LITERATURE REVIEW}

On a global scale, human population is significantly increasing in the coastal urban areas (DiDonato et al., 2009). Population growth increases impervious land, which significantly alters surface water quality (Nagy et al., 2012). Many studied have been conducted in identifying the major drivers of stream water quality. Li et al. (2014) evaluated the temporal and spatial variations of stream water quality of the Xin'anjiang River, China. They used multivariate statistical techniques (correlation analysis, cluster analysis, discriminant analysis, and principal component analysis) and found that the soluble salts (reflected by EC, COD, permanganate index, ammonianitrogen, and E. coli) were the main drivers of water quality in Xin'anjiag River. Kuppusamy and Giridhar (2006) investigated the interrelationships among different water quality indicator variables and attempted to infer the likely sources or controls of coastal water quality in Chennai Ennore, India. The study reported that the eutrophication factor (i.e., $\mathrm{pH}, \mathrm{DO}$, and suspended solids) had explained most of the observed variance in water quality datasets.

The hydrological changes because of urban development can magnify the impact of nonpoint source pollutions in streams and rivers. The potential changes may include permanent alteration or transitional fluctuation in stream temperature, increased nutrient concentrations, and reduction in dissolved oxygen. Shrestha and Kazama (2007) identified variables that led to spatial and temporal changes in Fuji River Basin, Japan. The research used 13 water quality variables that

were collected over 8 years on a monthly interval. The study found that climate (temperature) and the discharging nutrient were the main determinants of water quality in Fuji River.

In the Northern Gulf of Mexico, Turner et al. (2007) identified the major controls of stream water quality. They found that discharging total nitrogen and total phosphorus from the Mississippi 
and Atchafalaya Rivers led to a major reduction in the quality of Gulf of Mexico. Nagy et al. (2012) investigated stream water quality by developing multiple regression models in the Apalachicola River Basin, Florida. They found that watershed with greatest impervious area exhibited higher in-stream $\mathrm{pH}$, specific conductance, and temperature. Santhi et al. (2005) identified the major sources of pollutants in the Trinity River Basin, Texas using Soil Water Assessment Tool (SWAT). This study found that sediment erosion and nutrients were the major causes of pollution in the Trinity River basin.

Most previous studies in this area and around the world were conducted by focusing on a relatively small spatial scale, and statistical models were developed without resolving the multicollinearity (mutual correlations among the predictors) issue that can lead to biased and misleading results. Abdul-Aziz and Ahmed (2017) employed partial least squares regression (PLSR) modeling to resolve the multicollinearity issue among the predictors. They determined the relative linkages of land use and hydrologic drivers with stream water quality in the coastal-urban watersheds of southeast Florida. The research found that Everglades was the major source of total nitrogen in the coastal-urban streams, whereas stream total phosphorus (the limiting nutrient) was primarily contributed by the agricultural lands that represented a small portion $(\sim 3 \%)$ of the draining watersheds. The thesis builds on the study of Abdul-Aziz and Ahmed to identify the major drivers of dissolved oxygen (DO) dynamics and their dynamic environmental linkages of DO in the coastal/urban streams across the Gulf Coast of U.S.A. 


\section{CHAPTER 3}

\subsection{Study Area}

\section{MATERIALS AND METHODS}

This study was conducted in the coastal/urban streams across the U.S. Gulf Coast (Figure 1). Based on the availability of long-term observations, 36 water quality monitoring stations were considered in this study. The selected stations represented a good spatial coverage, and incorporated the geographic, latitudinal, and longitudinal gradients along the Gulf Coast, which extends 1631 miles and covers $13.5 \%$ of the U.S coastal area (Kennicutt, 2017). It includes 5 U.S. states (Texas, Louisiana, Mississippi, Alabama, and west Florida) and mostly humid/warm temperate; however, the southwestern part of Florida represents a subtropical climate (Mulholland et al., 1997).

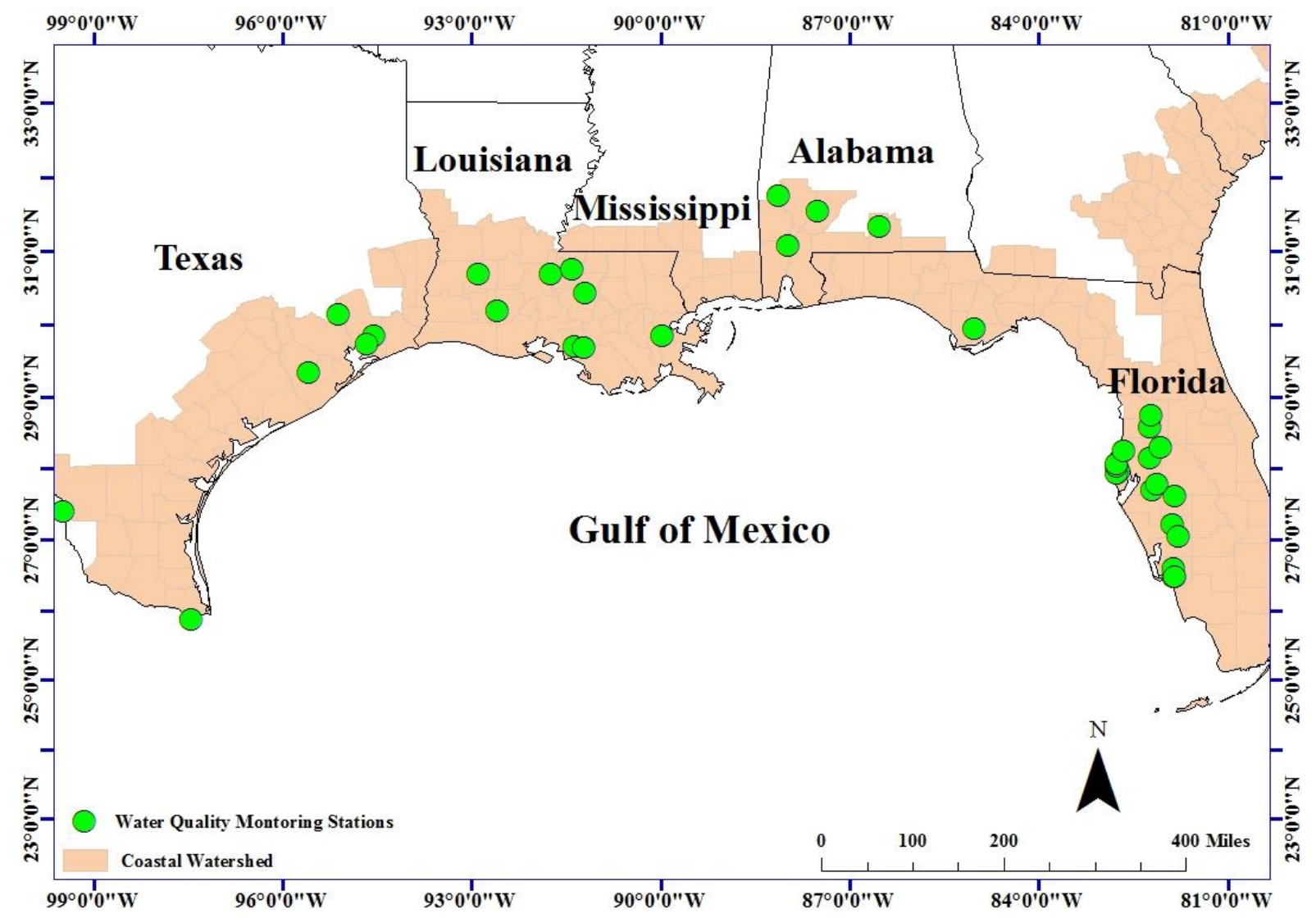

Figure 1: Study area, Coastal watershed, and the location of water quality monitoring stations. 


\subsection{Datasets}

The datasets of 36 stream water quality monitoring stations along the Gulf Coast States were gathered from the USGS NWIS and EPA STORET (NWQMC, 2017). The data often represented bimonthly samples between the years of 1998 and 2015. The selected water quality variables were: total nitrogen (TN), total phosphorus (TP), specific conductance (SC), potential of hydrogen $(\mathrm{pH})$, flow rate (Q), water temperature (TW), and dissolved oxygen (DO). Further, to include the impact of climatic processes on stream DO, hourly averaged data of atmospheric pressure (AP) and solar radiation (SR) were obtained from the National Solar Radiation Data Base (NSRDB, 2017). The variables were selected based on preliminary data analysis and leveraging the current understanding of the temporal variation of stream dissolved oxygen in the coastal urban/natural streams (Chambers et al., 2006; Kannel et al., 2011; Bayram et al., 2015). TP was the summation of inorganic, organic, and dissolved forms of phosphorus; and TN was the summation of nitrate, nitrite $\left(\mathrm{NO}_{2}{ }^{-}\right)$, ammonia $\left(\mathrm{NH}_{3}\right)$, and organic nitrogen. An interquartile range (IQR) criteria with a factor of two (i.e., median $\pm 2 * \mathrm{IQR}$ ) was used to remove outliers, which can distort the goodness of model fit (Aggarwal and Yu, 2001; Devarakonda et al., 2014). The sample size (n) of the temporal datasets ranged from 16 to 241 among the different sites (Table 1). 
Table 1: Ensemble mean and standard deviations (in parenthesis) of the observed stream DO and the dynamic environmental drivers across the the Gulf Coast of U.S.A.

\begin{tabular}{|c|c|c|c|c|c|c|c|c|c|c|c|c|}
\hline Station ID & I & Year & $\mathrm{n}$ & $\mathrm{TN}(\mathrm{mg} / \mathrm{L})$ & $\mathrm{TP}(\mathrm{mg} / \mathrm{L})$ & $\mathrm{SC}(\mu \mathrm{S} / \mathrm{cm})$ & $\mathrm{pH}$ & $\mathrm{Q}\left(\mathrm{m}^{3} / \mathrm{s}\right)$ & AP (mbar) & $\mathrm{TW}\left({ }^{\circ} \mathrm{C}\right)$ & $\mathrm{SR}\left(\mathrm{W} / \mathrm{m}^{2}\right)$ & $\mathrm{DO}(\mathrm{mg} / \mathrm{L})$ \\
\hline USGS-08475000 & TX_1 & $2000-14$ & 81 & $1.29(0.43)$ & $0.20(0.07)$ & $1354.27(246.95)$ & $7.90(0.28)$ & $9.52(6.16)$ & $1013.39(4.13)$ & $26.71(4.71)$ & $522.23(253.40)$ & $7.08(1.67)$ \\
\hline USGS-08459200 & TX_2 & 1999-07 & 57 & $1.36(0.40)$ & $.25(0.07)$ & $950.81(151.74)$ & $7.98(0.25)$ & $46.68(28.49)$ & $995.37(4.45)$ & $24.36(5.50)$ & 616.37(281.47) & 7.57(1.36) \\
\hline USGS-08042554 & TX_3 & $2008-15$ & 64 & $1.52(0.61)$ & $0.28(0.13)$ & $711.92(270.04)$ & $8.05(0.23)$ & $90.77(112.38)$ & 1014.51(4.97) & 24.44(7.01) & $625.82(251.80)$ & $8.18(1.76)$ \\
\hline USGS-08042546 & TX_4 & 1998-08 & 21 & $5.13(1.74)$ & $1.34(0.56)$ & $482.71(193.21)$ & $7.58(0.31)$ & $6.97(7.50)$ & $1009.88(3.68)$ & $24.47(5.12)$ & $550.60(304.40)$ & $6.34(1.35)$ \\
\hline USGS-08116650 & TX_5 & 1998-13 & 77 & $5.01(2.30)$ & $1.02(0.50)$ & $441.43(141.66)$ & $7.63(0.48)$ & $2.71(3.16)$ & $1011.76(4.50)$ & $22.54(6.19)$ & $558.44(247.63)$ & $8.86(2.09)$ \\
\hline USGS-08070200 & TX_6 & $1998-13$ & 64 & $0.59(0.19)$ & $0.09(0.03)$ & $192.09(36.53)$ & $7.02(0.21)$ & $1.71(1.44)$ & $1013.48(4.87)$ & $21.30(6.14)$ & $586.84(240.53)$ & $8.00(1.58)$ \\
\hline USGS-08012150 & LA_1 & 1998-02 & 16 & $1.35(0.42)$ & $0.23(0.08)$ & 153.81(100.77) & $7.25(0.43)$ & $111.00(111.40)$ & $1016.08(2.68)$ & $19.50(6.11)$ & $402.09(182.13)$ & $4.24(1.71)$ \\
\hline USGS-08014500 & LA_2 & $1998-13$ & 38 & $0.34(0.09)$ & $0.04(0.01)$ & $51.82(6.15)$ & $6.75(0.49)$ & $9.38(5.27)$ & $1015.28(4.23)$ & 20.01(5.14) & $544.71(246.27)$ & $8.46(1.21)$ \\
\hline USGS-07381590 & LA_3 & & 130 & $1.90(0.57)$ & $0.22(0.06)$ & $358.15(90.65)$ & $7.76(0.25)$ & $3539.87(1621.42)$ & $1016.71(4.48)$ & $20.13(7.38)$ & $596.26(230.62)$ & $7.69(2.04)$ \\
\hline USGS-07381495 & LA_4 & $1998-15$ & 241 & $1.85(0.58)$ & $0.22(0.06)$ & $353.98(93.57)$ & $7.76(0.26)$ & $7040.87(3587.22)$ & $1015.24(4.83)$ & 18.68(7.99) & $597.72(222.75)$ & $8.43(2.02)$ \\
\hline USGS-07381600 & LA_5 & $1998-15$ & 131 & $1.84(0.55)$ & $0.21(0.06)$ & $361.76(89.51)$ & $7.75(0.25)$ & $4260.84(2089.59)$ & $1016.26(4.55)$ & $20.12(7.61)$ & $561.47(258.63)$ & $7.55(2.26)$ \\
\hline USGS-07373420 & LA_6 & $1998-15$ & 232 & $2.11(0.61)$ & $0.23(0.07)$ & $380.50(64.41)$ & $7.79(0.25)$ & $15946.17(7468.16)$ & $1012.45(4.85)$ & $17.87(8.27)$ & $579.05(235.97)$ & $8.80(2.04)$ \\
\hline USGS-07374000 & LA_7 & 2004-15 & 138 & $2.12(0.56)$ & $0.23(0.06)$ & $384.50(64.36)$ & $7.89(0.18)$ & $16294.50(7930.02)$ & $1014.39(4.65)$ & $17.41(8.16)$ & $610.43(269.49)$ & $8.92(2.11)$ \\
\hline USGS-07374525 & LA_8 & 2006-15 & 119 & $2.14(0.58)$ & $0.25(0.07)$ & $404.12(76.41)$ & $7.82(0.20)$ & $16949.42(7392.70)$ & 1017.33(4.63) & $18.26(8.10)$ & $681.76(240.63)$ & $8.53(2.16)$ \\
\hline USGS-02470500 & AL_1 & $2007-15$ & 89 & $0.68(0.11)$ & $0.10(0.04)$ & $175.74(60.18)$ & $7.37(0.33)$ & $1744.38(1125.14)$ & $1010.58(5.64)$ & $18.65(7.17)$ & $588.53(251.28)$ & $9.33(1.58)$ \\
\hline USGS-02469762 & AL_2 & $1999-15$ & 89 & $0.70(0.15)$ & $0.10(0.05)$ & $201.79(71.50)$ & $7.47(0.27)$ & 781.51(897.02) & 1010.48(4.96) & $20.54(7.67)$ & $562.43(218.96)$ & $9.66(1.63)$ \\
\hline USGS-02429500 & AL_3 & $1999-15$ & 46 & $0.55(0.08)$ & $0.07(0.01)$ & $165.30(34.33)$ & $7.52(0.24)$ & $577.97(518.71)$ & $1008.50(4.16)$ & $21.39(6.60)$ & $589.48(243.57)$ & $9.15(1.75)$ \\
\hline *21AWIC-7870 & AL_4 & 2012-15 & 28 & $0.53(0.15)$ & $0.02(0.01)$ & 76.49(12.07) & 7.13(0.24) & $25.58(30.39)$ & $1005.08(4.51)$ & $20.98(6.98)$ & 453.11(184.52) & $7.68(2.06)$ \\
\hline
\end{tabular}

Note: (1) TX, LS, and AL, respectively, refer to stations in Texas, Louisiana, and Alabama. (2) "n" is the sample size. (3) TN, TP, SC, pH, Q, AP, SR, TW, and DO, respectively, refer to total nitrogen, total phosphorus, specific conductance, potential of hydrogen, flow rate, atmospheric pressure, solar radiation, water temperature, and dissolved oxygen. (4) * STORET water quality station. (5) "I" is station identifier. 
Table1 (continued): Ensemble mean and standard deviations (in parenthesis) of the observed stream DO and the dynamic environmental drivers across the the Gulf Coast of U.S.A.

Note: (1) FL refers to stations in Florida. (2) " $n$ " is the sample size. (3) TN, TP, SC, pH, Q, AP, SR, TW, and DO, respectively, refer to total nitrogen,

\begin{tabular}{|c|c|c|c|c|c|c|c|c|c|c|c|c|}
\hline Station ID & $\mathrm{I}$ & Year & $\mathrm{n}$ & $\mathrm{TN}(\mathrm{mg} / \mathrm{L})$ & $\mathrm{TP}(\mathrm{mg} / \mathrm{L})$ & $\mathrm{SC}(\mu \mathrm{S} / \mathrm{cm})$ & $\mathrm{pH}$ & $\mathrm{Q}\left(\mathrm{m}^{3} / \mathrm{s}\right)$ & AP (mbar) & $\mathrm{TW}\left({ }^{\circ} \mathrm{C}\right)$ & $\mathrm{SR}\left(\mathrm{W} / \mathrm{m}^{2}\right)$ & $\mathrm{DO}(\mathrm{mg} / \mathrm{L})$ \\
\hline USGS-02359170 & FL_1 & $2008-15$ & 79 & $0.79(0.15)$ & $0.04(0.01)$ & $126.84(20.78)$ & $6.73(0.57)$ & $596.77(334.60)$ & 1017.42(4.09) & $20.92(6.68)$ & $722.82(227.94)$ & 7.99(1.91) \\
\hline USGS-02312600 & FL_2 & 1998-06 & 18 & $1.26(0.38)$ & $0.07(0.03)$ & 199.06(105.97) & $6.87(0.94)$ & $28.01(30.15)$ & $1016.21(4.26)$ & $20.40(5.77)$ & 498.69(204.72) & $4.21(2.43)$ \\
\hline USGS-02312500 & FL_3 & 1998-06 & 30 & $1.09(0.46)$ & $0.08(0.03)$ & 218.93(86.59) & $6.94(0.81)$ & $15.31(16.34)$ & $1015.06(4.64)$ & $21.70(5.39)$ & $611.37(204.25)$ & $5.45(1.60)$ \\
\hline USGS-02310947 & FL_4 & 2001-09 & 32 & $1.98(0.67)$ & $0.11(0.04)$ & $160.28(73.74)$ & $6.27(0.47)$ & $2.10(2.48)$ & $1013.36(2.66)$ & $22.73(2.95)$ & $573.86(240.05)$ & $4.06(1.31)$ \\
\hline USGS-02310300 & FL_5 & 1998-02 & 16 & $1.24(0.48)$ & $0.05(0.02)$ & $260.38(99.56)$ & $6.61(0.58)$ & $0.12(0.11)$ & $1016.05(3.39)$ & $21.26(3.43)$ & $628.28(210.24)$ & $4.70(1.03)$ \\
\hline USGS-02303000 & FL_6 & 1998-03 & 20 & $1.73(0.16)$ & $0.24(0.14)$ & $335.95(59.17)$ & $7.23(0.56)$ & $4.82(3.77)$ & 1015.35(3.49) & $23.50(2.76)$ & $609.10(201.53)$ & $6.12(0.86)$ \\
\hline USGS-02309445 & FL_7 & 2000-02 & 23 & $1.68(0.39)$ & $0.11(0.04)$ & $563.65(85.57)$ & $7.00(0.68)$ & $0.03(0.02)$ & 1017.54(3.20) & $23.79(3.13)$ & $515.91(181.96)$ & $6.50(0.72)$ \\
\hline USGS-02309425 & FL_8 & 1999-02 & 31 & $1.46(0.49)$ & $0.23(0.05)$ & $556.00(68.55)$ & $7.09(0.81)$ & $0.25(0.16)$ & $1018.08(4.11)$ & $22.61(4.75)$ & 493.71(166.61) & $7.24(1.11)$ \\
\hline USGS-02307671 & FL_9 & 1999-02 & 32 & $1.12(0.22)$ & $0.11(0.05)$ & $466.53(63.75)$ & $7.13(0.74)$ & $0.13(0.11)$ & $1018.29(3.79)$ & $22.85(4.51)$ & $423.10(227.75)$ & $5.67(1.29)$ \\
\hline USGS-02307731 & FL_10 & 1999-02 & 27 & $0.81(0.33)$ & $0.19(0.07)$ & 413.07(81.49) & $7.07(0.75)$ & $0.06(0.07)$ & $1018.29(4.32)$ & $22.22(5.00)$ & $437.15(299.33)$ & $5.91(1.16)$ \\
\hline USGS-02301300 & FL_11 & 1998-03 & 34 & $1.08(0.27)$ & $0.74(0.23)$ & $353.62(65.56)$ & $7.35(0.72)$ & $2.61(3.20)$ & $1014.60(3.12)$ & $22.43(5.01)$ & $614.10(216.97)$ & $7.05(2.17)$ \\
\hline USGS-02300100 & FL_12 & 1998-03 & 30 & $0.93(0.33)$ & $0.51(0.16)$ & $333.50(128.14)$ & $7.04(0.78)$ & $0.45(0.62)$ & 1014.87(3.67) & $21.34(4.36)$ & 695.03(222.61) & $7.09(1.37)$ \\
\hline USGS-02295420 & FL_13 & 1999-04 & 33 & $1.55(0.43)$ & $0.80(0.12)$ & $399.48(51.47)$ & $7.45(0.64)$ & $2.20(2.47)$ & $1018.57(4.83)$ & $22.26(4.63)$ & $635.65(243.41)$ & $7.17(1.29)$ \\
\hline USGS-02296750 & FL_14 & 1998-04 & 42 & $1.55(0.34)$ & $0.95(0.23)$ & $385.69(104.76)$ & $7.48(0.50)$ & $20.51(19.76)$ & 1016.93(3.98) & $23.90(5.40)$ & $710.82(194.65)$ & $7.05(1.40)$ \\
\hline USGS-02298123 & FL_15 & 1998-03 & 26 & $1.37(0.33)$ & $0.09(0.06)$ & $740.31(221.59)$ & $7.29(0.70)$ & $3.65(3.61)$ & 1017.79(4.92) & $23.58(5.28)$ & 484.92(220.56) & $6.20(1.69)$ \\
\hline *WQX-10MIGR10 & FL_16 & $2009-14$ & 43 & $1.03(0.33)$ & $0.03(0.01)$ & $11297.21(12091.23)$ & $7.44(0.08)$ & $3.67(3.14)$ & 1017.41(2.95) & $25.93(3.40)$ & $664.19(162.04)$ & $5.27(1.04)$ \\
\hline *WQX-10MIGR80 & FL_17 & $2009-13$ & 28 & $1.08(0.29)$ & $0.02(0.01)$ & $690.54(133.87)$ & $7.55(0.23)$ & $0.47(0.27)$ & $1018.58(4.22)$ & $24.03(4.89)$ & $439.18(139.24)$ & $5.86(2.48)$ \\
\hline *WQX-46B-9GR & FL_18 & 2009-14 & 49 & $1.06(0.29)$ & $0.02(0.01)$ & $836.82(55.40)$ & $7.37(0.17)$ & $1.82(1.01)$ & $1017.03(2.60)$ & $24.97(2.37)$ & 711.05(186.99) & $4.91(1.86)$ \\
\hline
\end{tabular}

total phosphorus, specific conductance, potential of hydrogen, flow rate, atmospheric pressure, solar radiation, water temperature, and dissolved oxygen. (4) *21FLEECO STORET water quality station. (5) "I" is station identifier. 


\subsection{The Data Analytics Framework}

A systematic data analytics approach (Figure 2) (Abdul-Aziz and Ahmed, 2017) was utilized to identify the dominant controls of stream DO in the Gulf Coast of U.S.A. Before applying data analytics, the data for all variables were $\log$-transformed $(\log 10)$ to incorporate any nonlinear correspondences and achieve a relatively constant variance of potential model residuals (i.e. homoscedasticity) (Box and Cox, 1964). The log-transformed data were standardized to compute the respective Z-scores (Abdul-Aziz and Ahmed, 2017) as follows: $Z=(X-\bar{X}) / S_{X}$, where $X=$ $\log 10$-transformed variable, $\bar{X}=$ mean of X, $S_{x}=$ standard deviation of X. The data centralization and normalization brought different values and units of variables to a common reference scale. First, Pearson's correlation analysis was applied to have a preliminary information on the nonlinear correspondences and multicollinear structure of the datasets. Second, principal component analysis (PCA) was conducted to reduce redundant dimensions, while retaining the variation present in the dataset (Jolliffe, 2002). Third, factor analysis (FA) was applied to reanalyze the standardized data and support findings from PCA by explaining the system data variances with fewer latent variables (factors) (Johnson and Wichern, 1992). Finally, partial least squares regression (PLSR) (Wold et al., 1993, 2001) was applied to estimate the relative linkages and dominant controls of stream DO by appropriately resolving any multicollinearity present in the data matrix. Each layer of data analytics was performed with the standardized data using MATLAB. Further details into the data analytics methods can be found in Abdul-Aziz and Ahmed (2017). 
Step-1: Determine the mutual correspondences and multicollinear structure of dissolved oxygen with dynamic environmental drivers

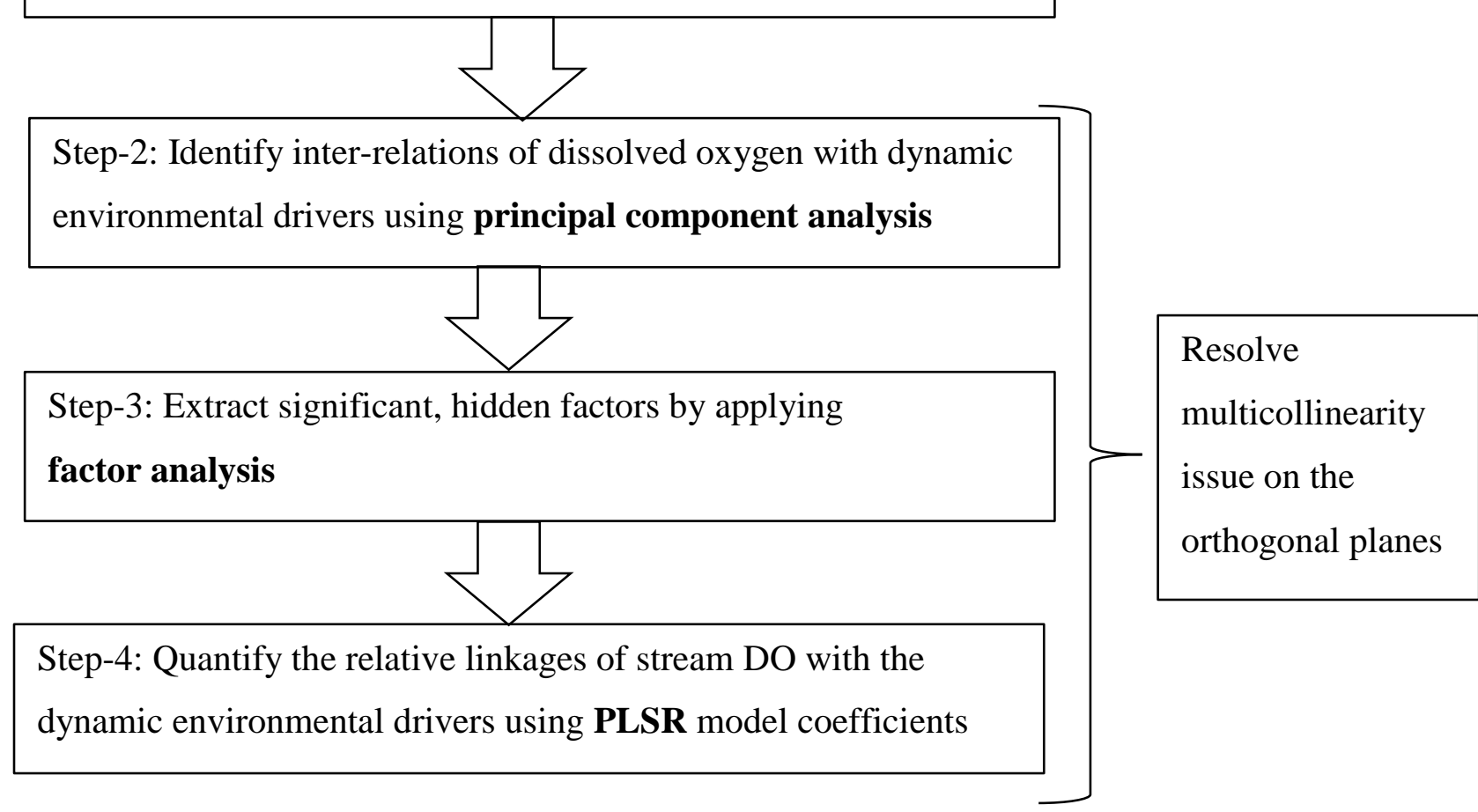

Figure 2: The data analytics framework to determine the relative linkages of stream dissolved oxygen with the dynamic environmental drivers.

PLSR models with a bootstrap Monte Carlo procedure (1000 iterations) were developed to obtain a robust estimation of the relative linkages of stream DO with the dynamic environmental drivers. The PLSR models were trained (i.e., fitted) and verified (i.e., tested) with the observed data using SIMPLS algorithm (de Jong, 1993) and a 10-fold cross-validation (Kuhn and Johnson, 2013). The optimality of the models was achieved by involving a minimum number of partial least squares (PLS) components, which was determined based on a synthesis of eigenvalue $\geq 1$, maximum Nash-Sutcliffe Efficiency (NSE), and minimum Akaike Information Criterion (AIC) (Akaike, 1974). The developed model's goodness-of-fit was measured by NSE, and the accuracy of predictions was evaluated by the ratio of root-mean-square error to the standard deviation of 
observations (RSR). Each PLS component was a combination of all original environmental predictors of DO. The estimated, optimal PLSR models were therefore transformed back to the original (Z-scores) variable domain to compute the relative linkages (i.e., regression weights, $\beta$ ) of stream DO with the dynamic environmental drivers. The positive or negative sign of ' $\beta$ ' indicated the direction of relationship (i.e., increasing or decreasing) between predictors and stream dissolved oxygen. Based on mechanistic understanding, the dynamic drivers of DO were grouped in four environmental process-components: (1) 'climate' (TW and SR), (2) 'hydroatmospheric (Q and AP), (3) 'redox' (pH and SC), and (4) 'nutrients' (TN and TP). The aggregated linkages $\left(\beta_{\mathrm{C}}\right),\left(\beta_{\mathrm{H}}\right),\left(\beta_{\mathrm{R}}\right)$, and $\left(\beta_{\mathrm{N}}\right)$ for, respectively, the climatic, hydro-atmospheric, redox, and nutrient components were computed using the method of vector summation as follows:

$$
\begin{aligned}
& \beta_{C}=\sqrt{\beta_{T W}+\beta_{S R}} \\
& \beta_{H}=\sqrt{\beta_{Q}+\beta_{A P}} \\
& \beta_{R}=\sqrt{\beta_{p H}+\beta_{S C}} \\
& \beta_{N}=\sqrt{\beta_{T N}+\beta_{T P}}
\end{aligned}
$$




\section{CHAPTER 4}

\section{RESULTS}

\subsection{Mutual Correspondences of the Dynamic Environmental Drivers}

The nonlinear correspondences of stream DO with the dynamic environmental drivers were first determined by computing the Pearson correlation coefficients (Table A1) with the $\log _{10^{-}}$ transformed and standardized data. Three regions were identified based on dominant correlations of stream DO with the predictors. In the northern part of the Gulf Coast States (NGCS), 17 streams showed strong correlations between TW and DO. However, 3 streams in the southern part of the Gulf coast (SGCS) showed a notable correlation of TW and $\mathrm{pH}$ with stream DO. Further, 16 streams located between these two regions (i.e., in the "transition" region) demonstrated notable influence of multiple drivers (i.e., Q, SC, and TW) on stream DO. The results were further summarized by computing region-specific average correlation coefficients (Table 2).

In the northern part of the Gulf coast states, stream DO had a strong negative correspondence with TW $(r=-0.75)$, representing a water temperature dominated environmental regime of stream DO. In contrast, in the southern part of the Gulf coast region (southern Texas and south-western Florida), DO had a strong positive correlation with $\mathrm{pH}(\mathrm{r}=0.62)$, whereas moderate correlation with TW $(r=-0.49)$. Streams in the transition region were grouped into two environmental regimes: Q-dominated and SC-dominated. In the flow rate dominated regime, stream DO had strong correlations with $\mathrm{Q}(\mathrm{r}=-0.75)$ and TP $(\mathrm{r}=-0.60)$, whereas moderate correlation with $\mathrm{pH}(\mathrm{r}=0.49)$, TW $(\mathrm{r}=-0.48)$, and SC $(0.41)$. In specific conductance dominated regime, stream DO had a strong negative correlation with SC $(r=-0.73)$, whereas moderate correlations with Q $(r=0.58), \mathrm{pH}(\mathrm{r}=-0.49)$, and TW $(\mathrm{r}=-0.40)$. 
The correlation matrices (Table A2 to A5) showed strong mutual correspondences, indicating the presence of high multicollinearity among the dynamic environmental drivers. For example, flow rate had moderate to strong correlation with $\mathrm{TP}(\mathrm{r}=0.50)$ and $\mathrm{SC}(\mathrm{r}=-0.80)$. The negative correspondence indicates that $\mathrm{SC}$ decreased with increasing flow rate (i.e. dilution effect). In contrast, flow rate had a positive correlation with total phosphorus, this indicates that the concentration of TP increases with increasing flow rate (i.e., hydrologic effect due to increased runoff and sediment load). These findings were corroborated using scatter-plotting of flow rate with total phosphorus (Figure A1). AP had a moderate to strong correlation with SR $(\mathrm{r}=-0.46)$ and TW $(\mathrm{r}=-0.63)$. The negative correspondences indicated that atmospheric pressure reduces with increasing atmospheric temperature. TW had moderate positive correspondence with $\mathrm{TP}(\mathrm{r}=$ 0.59), indicating that TP increased with increasing metabolism as temperature of water increases.

Table 2: Ensemble mean Pearson correlation coefficients (r) of dissolved oxygen with dynamic environmental drivers of the three regions.

\begin{tabular}{llllllllll}
\hline Region & Regimes & TN & TP & SC & pH & Q & AP & TW & SR \\
\hline NGCS & TW dominated & -0.03 & -0.23 & 0.06 & 0.17 & -0.08 & 0.31 & -0.75 & -0.23 \\
Transition & Q dominated & 0.13 & -0.60 & 0.41 & 0.49 & -0.75 & 0.32 & -0.48 & -0.06 \\
& SC dominated & -0.09 & -0.25 & -0.73 & -0.49 & 0.58 & 0.33 & -0.40 & -0.12 \\
\multirow{2}{*}{ SGCS } & pH dominated & 0.00 & -0.16 & 0.14 & 0.62 & -0.25 & 0.29 & -0.49 & -0.13
\end{tabular}

Note: (1) Data of all variables were log10-transformed to incorporate the non-linear interaction. (2) TN, $\mathrm{TP}, \mathrm{SC}, \mathrm{pH}, \mathrm{Q}, \mathrm{AP}, \mathrm{TW}$, and $\mathrm{SR}$, respectively, refer to total nitrogen, total phosphorus, specific conductance, potential of hydrogen, flow rate, atmospheric pressure, water temperature, and solar radiation. (3) NGCS refers to Northern part of Gulf coast states. (4) SGCS refers to Southern part of Gulf coast states. 


\subsection{Relative Orientations and Interrelations of Stream DO with the Dynamic Environmental Drivers}

The nonlinear loadings of stream DO and various environmental drivers on the first two PCs are presented through biplots for four example streams, representing the four environmental regimes of stream DO across the U.S. Gulf Coast. The percentage variance explained by all individual PCs for each stream (Table A6) indicated that the first two PCs explained approximately $47 \%$ to $72 \%$ of the total data variance. Based on the orientation or linkages of dynamic environmental drivers with stream DO (Figure A2 to A5), stations were grouped into three regions, which were similar to that identified by the Pearson's correlation analyses.

In the northern part of the Gulf coast states, the first two PCs explained $48 \%$ to $72 \%$ of the total data variance. The orientations and lengths of TW and SR suggested their strong interrelationship, forming a negative linkage with DO (Figure 3a). Moreover, $\mathrm{pH}$ had a moderate negative linkage with DO. In contrast, AP, TN, and Q had moderate positive linkages with DO. Further, SC and TP had an orthogonal orientation with the response (DO), representing relatively weak or no linkage. In the southern part of the Gulf Coast region (southern Texas and southwestern Florida), the first two PCs explained $47 \%$ to $52 \%$ of the total data variance. The orientation and length of $\mathrm{pH}$ suggested its strong positive linkage with DO (Figure 3d). Moreover, AP had moderate positive linkage with DO. In contrast, Q, TW, and SC had moderate/strong negative linkages with DO.

Streams in in the "transition" region showed mixed dominance of Q, SC, and TW on DO. In flow rate dominated regime, the first two PCs explained $62 \%$ of the total data variance. The orientation and length of TP and Q suggest their strong interrelationship, forming a strong negative

linkage with DO (Figure 3b). Moreover, TW and SR had strong interrelationship, forming a 
moderate negative linkage with $\mathrm{DO}$. In contrast, $\mathrm{SC}, \mathrm{AP}, \mathrm{pH}$, and $\mathrm{TN}$ had moderate positive linkages with DO. In specific conductance dominated regime, the first two PCs explained 58\% to $64 \%$ of the total data variance exhibited by the dynamic environmental drivers. The orientation and length of $\mathrm{SC}, \mathrm{pH}$, and TN suggest their strong interrelationships, forming a negative linkage with DO (Figure 3c). Moreover, DO had a moderate negative linkage with TW and a strong positive linkage with Q for streams located in this regime.

The biplots (Figure 3) also showed the strong interrelationships among the dynamic environmental drivers of stream DO, indicating the presence of multicollinearity in data. The orientations and lengths of Q, TP, and TN (Figure 3a) showed their strong interrelationships, indicating that flow rate brings in nitrogen and phosphorus from the agricultural area (i.e. hydrologic effect). The orientations and lengths of TW and SR (Figure 3b) suggested their strong interrelationships, given that SR is the primary source of energy that causes stream heating. 
(a)

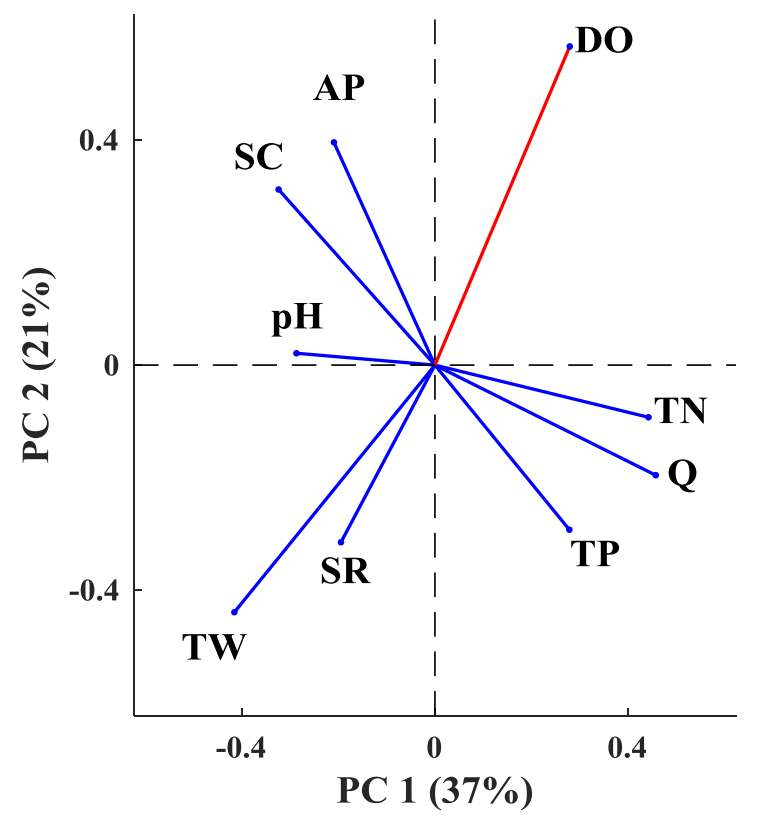

(c)

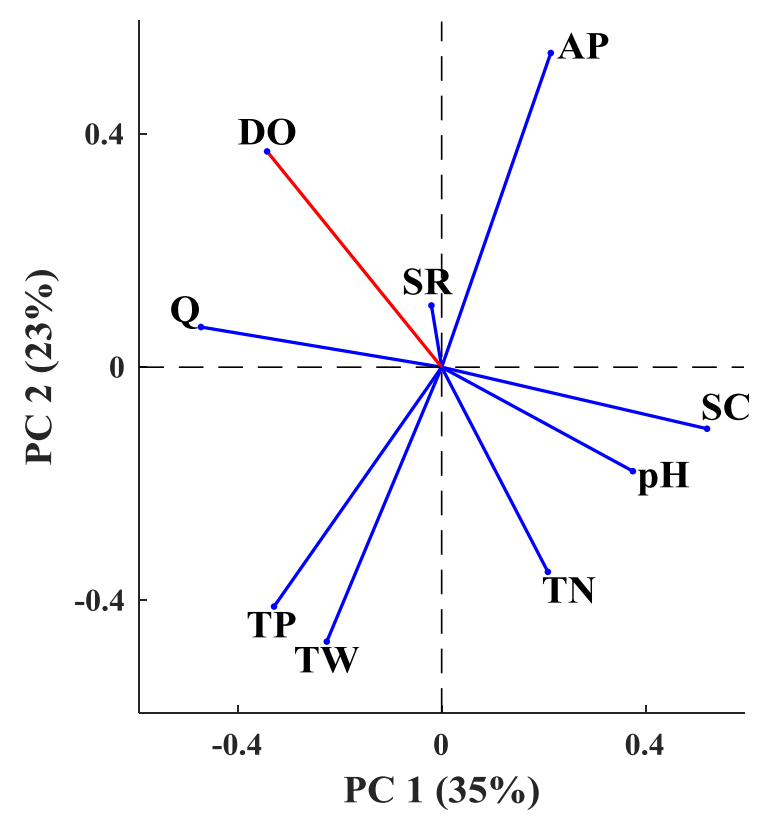

(b)

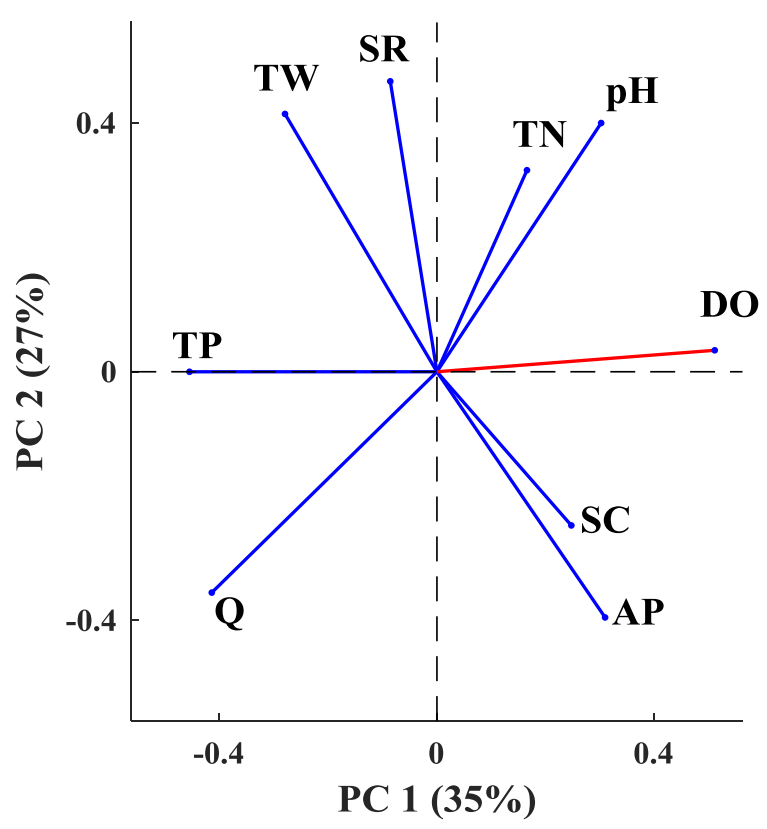

(d)

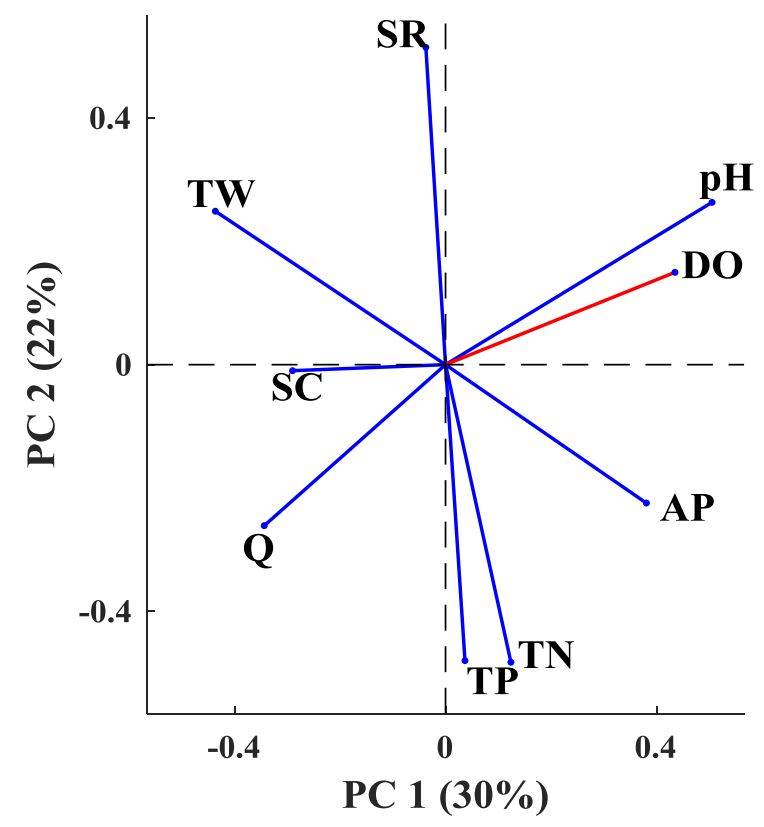

Figure 3: Representative biplots of the three regions obtained from principal component analysis, showing the interrelations of dissolved oxygen with dynamic environmental drivers: (a) TW dominated regime, (b) $\mathrm{Q}$ dominated regime, (c) SC dominated regime, and (d) $\mathrm{pH}$ dominated regime. 


\subsection{Major Water Quality Drivers Based on Independent Latent Factors}

Three regions were identified based on streams that showed similar dominant controls of DO based on FA. The identified regions were consistent with the Pearson correlation analyses and PCA. FA results are shown for example stations to represent different environmental regimes within the three regions across the Gulf Coast (Table 3). . Higher loadings of DO and the dynamic environmental drivers on the same factors indicates their strong interrelations.

In the northern part of the Gulf coast states, FA resulted in three to four independent latent factors to optimally demonstrate the hidden patterns in stream dissolved oxygen with the dynamic environmental drivers (Table 3). The 3 to 4 latent factors explained $61 \%$ to $88 \%$ of the total data variance. DO and TW typically loaded highly on factor 1 for most streams in this region (Table A7).. On average across the NGCS region, stream DO loaded very strongly on factor $1(0.99)$, which had a high loading of water temperature (-0.93) and a notable loading of SR (-0.34) and pH (0.36) (Table 3); however, the loadings of DO on factor 2 and 3 were very weak.

In the southern part of the Gulf coast states (southern Texas and south-western Florida), FA resulted in 3 independent latent factors to optimally demonstrate the hidden patterns of stream dissolved oxygen with the dynamic environmental drivers (Table 3). The 3 latent factors explained $61 \%$ to $67 \%$ of the total data variance. Two streams in this region showed that DO moderately loaded on factor 1, whereas a single stream showed that stream DO loaded highly on factor 2 (Table A7). On average across the SGCS region, stream DO strongly loaded on factor $1(0.73)$, which had a high loading of $\mathrm{pH}(0.96)$ and moderate loading of $\mathrm{Q}(-0.50)$ (Table 3).

Streams in in the "transition" region showed dominance of multiple drivers (i.e., Q, SC., and TW) on DO. In flow rate dominated regime, FA resulted in 3 independent latent factors to optimally demonstrate the hidden patterns of stream DO in relation to the dynamic environmental 
drivers (Table 3). The 3 independent latent factors explained $72.54 \%$ of the total data variance. Dissolved oxygen highly loaded on factor 1 (0.87), which had a high loading of Q (-0.98) and moderate loading of TP (-0.55) and $\mathrm{pH}(0.63)$. Moreover, DO notably loaded on factor $3(-0.45)$, which had a high loading of TW (0.72). In specific conductance dominated regime, FA resulted in 3 independent latent factors to optimally demonstrate the hidden patterns in data (Table 3 ). The 3 independent latent factors explained $73 \%$ to $81 \%$ of the total data variance. DO strongly loaded on factor 1 (-0.68), which had high loadings of SC (0.98) and Q (-0.84).

Table 3: Representative factors with their optimized loading on stream DO and corresponding dynamic environmental drivers of the identified three regions.

\begin{tabular}{|c|c|c|c|c|c|c|c|c|c|c|c|}
\hline Regions & Regimes & $F$ & $\mathrm{TN}$ & $\mathrm{TP}$ & $\mathrm{SC}$ & $\mathrm{pH}$ & $\mathrm{Q}$ & AP & TW & $\overline{S R}$ & $\mathrm{DO}$ \\
\hline \multirow[t]{3}{*}{ NGCS } & \multirow[t]{3}{*}{ TW dominated } & 1 & -0.04 & 0.02 & -0.17 & 0.36 & 0.03 & 0.24 & -0.93 & -0.34 & 0.99 \\
\hline & & 2 & -0.01 & -0.28 & 0.89 & 0.59 & -0.88 & 0.07 & 0.24 & 0.06 & 0.09 \\
\hline & & 3 & 1.00 & 0.37 & 0.15 & -0.07 & 0.19 & -0.04 & 0.02 & 0.11 & -0.04 \\
\hline \multirow[t]{6}{*}{ Transition } & \multirow[t]{3}{*}{ Q dominated } & 1 & 0.34 & -0.55 & 0.30 & 0.63 & -0.98 & 0.07 & -0.06 & 0.16 & 0.87 \\
\hline & & 2 & -0.09 & 0.45 & -0.26 & 0.10 & -0.03 & -0.92 & 0.56 & 0.45 & -0.20 \\
\hline & & 3 & 0.41 & 0.07 & -0.20 & 0.07 & -0.20 & -0.16 & 0.72 & 0.25 & -0.45 \\
\hline & \multirow[t]{3}{*}{ SC dominated } & 1 & 0.31 & -0.18 & 0.98 & 0.52 & -0.84 & 0.14 & -0.05 & 0.00 & -0.68 \\
\hline & & 2 & -0.02 & 0.98 & -0.20 & -0.21 & 0.09 & -0.46 & 0.57 & 0.16 & -0.04 \\
\hline & & 3 & -0.43 & -0.12 & 0.05 & -0.19 & -0.13 & 0.75 & -0.29 & 0.35 & 0.29 \\
\hline \multirow[t]{3}{*}{ SGCS } & \multirow[t]{3}{*}{$\mathrm{pH}$ dominated } & 1 & -0.09 & -0.06 & -0.37 & 0.96 & -0.50 & 0.18 & -0.30 & 0.19 & 0.73 \\
\hline & & 2 & 0.23 & 0.00 & -0.09 & 0.24 & -0.03 & 0.98 & -0.50 & -0.24 & 0.05 \\
\hline & & 3 & 0.55 & 0.62 & -0.14 & -0.11 & 0.06 & 0.04 & -0.34 & -0.44 & 0.15 \\
\hline
\end{tabular}

Note: (1) Bold value indicated variables having moderate to high loading on factor (F); F1-3 refers to three independent factors, (2) TN, TP, SC, pH, Q, AP, SR, and DO respectively refers to total nitrogen, total phosphorus, specific conductance, potential of hydrogen, flow rate, atmospheric pressure, water temperature, solar radiation, and dissolved oxygen. (3) NGCS refers to Northern part of Gulf coast states. (4) SGCS refers to Southern part of Gulf coast states. 


\subsection{Estimation of the Relative Linkages of Stream DO with the Predictors}

The optimality of PLSR models was achieved based on the synthesis of the minimum AIC, maximum NSE, and eigenvalue $\geq 1$ criteria, which suggested the first 3 to 4 PLS components (Figure 4). The models were robustly estimated with a 10-fold cross-validation method; the optimal models provided good predictions (Figure A8). The model intercept was "zero" for all stations since Z-score variables were used for model fitting. From PLSR results (Table A8), streams that have similar dominant drivers of stream DO were grouped into three regions and environmental regimes (Figure A6). The PLSR results were explained based on the mean of beta linkages for each region (Table 4). 
(a)
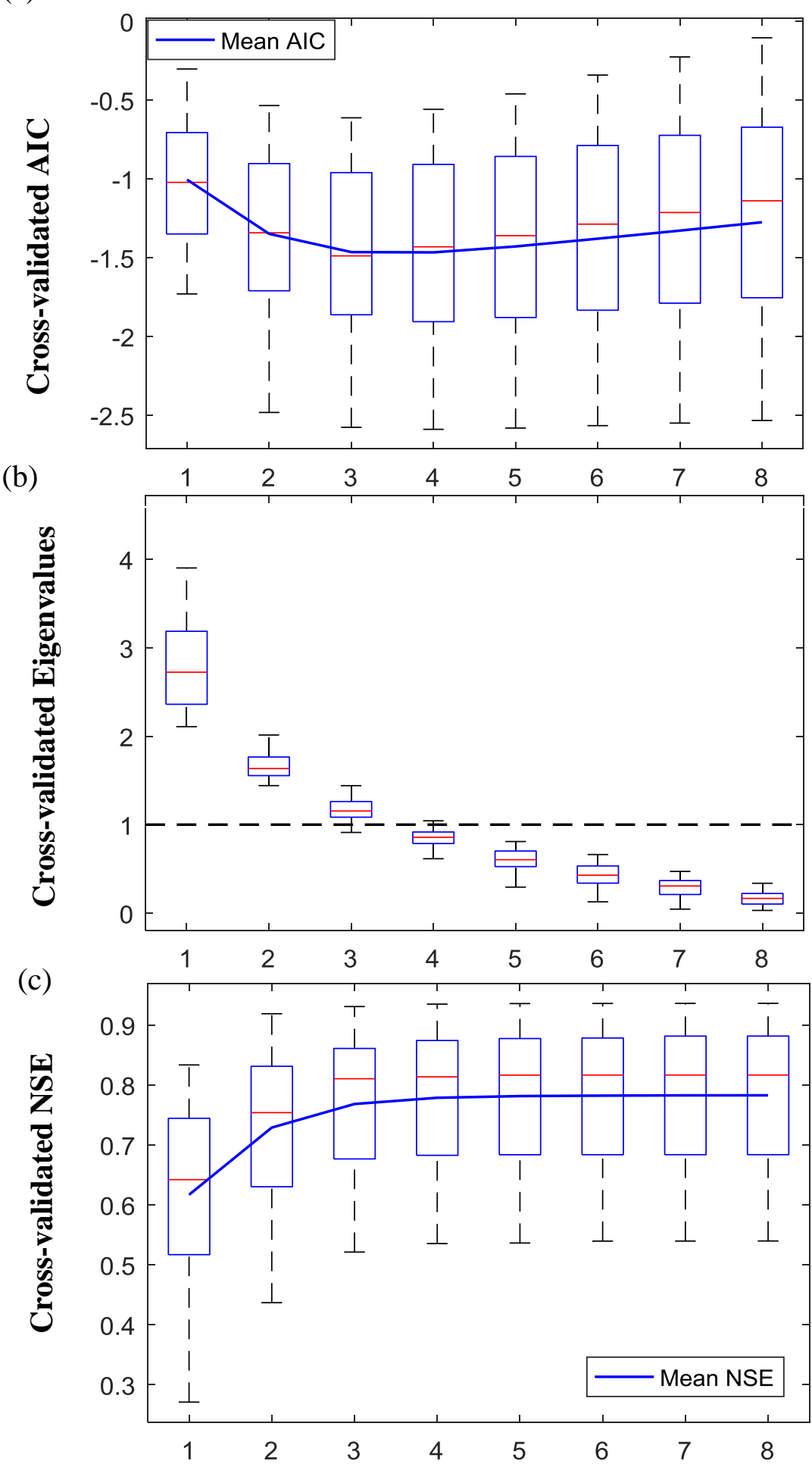

Figure 4: Plot of cross-validated (a) normalized AIC, (b) Eigenvalue, and (c) Nash-Sutcliffe efficiency (NSE) with the number of incorporated partial least square components of all stations. 
In the northern part of the Gulf coast states, DO had the strongest negative linkages with $\mathrm{TW}\left(\beta_{\mathrm{TW}}=-0.74\right)$. Notable linkages of $\mathrm{DO}$ were also apparent with $\mathrm{TP}\left(\beta_{\mathrm{TP}}=-0.13\right)$ and $\mathrm{pH}$ $\left(\beta_{\mathrm{pH}}=0.11\right)$. Based on the aggregated linkages (Eqs. 3-6), the climate components showed 2.7, 3.1, and 3.6 times stronger linkages with dissolved oxygen than that of the redox, nutrient, and hydro-atmospheric components, respectively (Table 5). In contrast, for the southern part of the Gulf coast states (Southern Texas and south-west Florida), stream DO had strong positive linkages with $\mathrm{pH}\left(\beta_{\mathrm{pH}}=0.56\right)$. Notable linkages of DO were also apparent with TW $\left(\beta_{\mathrm{TW}}=-0.35\right)$ and SC $\left(\beta_{\mathrm{SC}}=0.16\right)$ in this region. Based on the aggregated beta linkages, the redox components showed 1.6, 2.3, and 2.6 times stronger linkages with dissolved oxygen than that of the climate, nutrients, and hydroatmospheric components, respectively (Table 5).

Streams in the transition region showed multiple dominant drivers (i.e., Q and SC) of DO along with water temperature. The transition region was divided into two environmental regimes In the flow rate dominated regime, DO had strong linkages with $\mathrm{TW}\left(\beta_{\mathrm{TW}}=-0.49\right)$ and $\mathrm{Q}$ $\left(\beta_{\mathrm{Q}}=-0.58\right)$. Notable linkages of DO were also apparent with $\mathrm{SC}\left(\beta_{\mathrm{SC}}=0.20\right), \mathrm{pH}\left(\beta_{\mathrm{pH}}=\right.$ $0.20)$, and $\mathrm{TN}\left(\beta_{\mathrm{TN}}=-0.11\right)$. Based on the aggregated linkages, the hydro-atmospheric components showed 1.2, 2.0, and 3.4 times stronger linkages with dissolved oxygen than that of the climate, redox, and nutrient components, respectively (Table 5). In specific conductance dominated regime, DO had the strongest linkages with $\mathrm{SC}\left(\beta_{\mathrm{SC}}=-0.43\right)$. Notable linkages of DO were also apparent with TW $\left(\beta_{\mathrm{TW}}=-0.23\right)$ and $\mathrm{Q}\left(\beta_{\mathrm{Q}}=0.21\right)$. Based on the aggregated linkages, the redox components showed 1.3, 1.4, and 1.6 times stronger linkages with dissolved oxygen than that of the hydroatmospheric, climate, and nutrient components, respectively (Table 5). 
Table 4: Ensemble mean and standard deviation (in parenthesis) of the beta linkages after 1000 Monte Carlo simulations for the identified regions.

\begin{tabular}{lcccc}
\hline Regions & NGCS & \multicolumn{2}{c}{ Transition } & SGCS \\
& TW dominated & Q dominated & SC dominated & pH dominated \\
\hline TN & $0.01(0.11)$ & $-0.11(0.09)$ & $-0.01(0.21)$ & $-0.08(0.13)$ \\
TP & $-0.13(0.11)$ & $-0.09(0.10)$ & $-0.06(0.16)$ & $-0.07(0.12)$ \\
SC & $0.03(0.10)$ & $0.20(0.09)$ & $-0.43(0.13)$ & $0.16(0.11)$ \\
pH & $0.11(0.12)$ & $0.20(0.11)$ & $-0.02(0.15)$ & $0.56(0.11)$ \\
Q & $-0.03(0.11)$ & $-0.58(0.13)$ & $0.21(0.16)$ & $0.03(0.12)$ \\
AP & $0.01(0.11)$ & $-0.06(0.10)$ & $0.11(0.21)$ & $-0.02(0.12)$ \\
TW & $-0.74(0.12)$ & $-0.49(0.13)$ & $-0.23(0.20)$ & $-0.35(0.12)$ \\
SR & $-0.02(0.11)$ & $0.04(0.12)$ & $-0.01(0.14)$ & $0.04(0.13)$ \\
Model Statistics & & & & \\
$*$ OPC & $3-4$ & 3 & 3 & 3 \\
NSE & 0.80 & 0.90 & 0.80 & 0.68 \\
RSR & 0.43 & 0.28 & 0.41 & 0.56 \\
\hline NSE & & & & \\
\hline
\end{tabular}

Note: (1) *OPC refers to the number of optimum partial least square components. (2) TN, TP, SC, pH, Q, AP, TW, and SR respectively, refer to total nitrogen, total phosphorus, specific conductance, potential of hydrogen, flow rate, atmospheric pressure, water temperature, and solar radiation. (3) NGCS refers to Northern part of Gulf coast states. (4) SGCS refers to Southern part of Gulf coast states.

Table 5: Aggregated relative linkages of the process components for the four regimes after 1000 Monte Carlo simulation with mean and standard deviation (in parenthesis).

\begin{tabular}{lcccc}
\hline Aggregated components & TW dominated & Q dominated & SC dominated & pH dominated \\
\hline$\beta_{\mathrm{C}}$ & $0.77(0.12)$ & $0.51(0.10)$ & $0.33(0.15)$ & $0.38(0.12)$ \\
$\beta_{\mathrm{H}}$ & $0.21(0.09)$ & $0.59(0.13)$ & $0.34(0.14)$ & $0.23(0.10)$ \\
$\beta_{\mathrm{R}}$ & $0.28(0.10)$ & $0.30(0.09)$ & $0.46(0.13)$ & $0.59(0.11)$ \\
$\beta_{\mathrm{N}}$ & $0.25(0.09)$ & $0.18(0.08)$ & $0.28(0.14)$ & $0.26(0.09)$ \\
& \multicolumn{4}{c}{ Ratio to the Strongest $\beta$} \\
& $\beta_{\mathrm{C}} / \beta_{\mathrm{H}}=3.6$ & $\beta_{\mathrm{H}} / \beta_{\mathrm{C}}=1.2$ & $\beta_{\mathrm{R}} / \beta_{\mathrm{C}}=1.3$ & $\beta_{\mathrm{R}} / \beta_{\mathrm{C}}=1.6$ \\
& $\beta_{\mathrm{C}} / \beta_{\mathrm{R}}=2.7$ & $\beta_{\mathrm{H}} / \beta_{\mathrm{R}}=2.0$ & $\beta_{\mathrm{R}} / \beta_{\mathrm{H}}=1.4$ & $\beta_{\mathrm{R}} / \beta_{\mathrm{H}}=2.6$ \\
& $\beta_{\mathrm{C}} / \beta_{\mathrm{N}}=3.1$ & $\beta_{\mathrm{H}} / \beta_{\mathrm{N}}=3.4$ & $\beta_{\mathrm{R}} / \beta_{\mathrm{N}}=1.6$ & $\beta_{\mathrm{R}} / \beta_{\mathrm{N}}=2.3$ \\
\hline
\end{tabular}

Note: (1) The aggregated relative linkages of the 'climate components' $\left(\beta_{\mathrm{C}}\right)$, 'hydroatmospheric components' $\left(\beta_{\mathrm{H}}\right)$, 'redox components' $\left(\beta_{\mathrm{R}}\right)$, and the 'nutrient components' $\left(\beta_{\mathrm{N}}\right)$ were calculated, respectively, by using Eqs. 1-4. 


\section{CHAPTER 5}

\section{DISCUSSION AND CONCLUSIONS}

\subsection{Discussion}

Based on the finding from the systematic data analytics approach, streams were grouped into three regions along the U.S. Gulf Coast (Figure 7A). In the Northern part of Gulf Coast states (Texas, Louisiana, Mississippi, Alabama, and West Florida), water temperature (and the climate process component) had the strongest control on stream DO. However, in the southern part of Texas and Florida, clear dominance of $\mathrm{pH}$ and the redox component on stream DO were found. Further, streams in between this two regions (i.e., in the "transition" region) showed mixed dominance of multiple drivers (e.g., water temperature, TW; flow rate, Q; specific conductivity, SC) on the DO.

The strong negative linkages of stream dissolved oxygen with water temperature in the northern part of Gulf Coast states can be attributed to the reduction of solubility of DO at higher temperature. As water temperature increases, the solubility of dissolved oxygen reduces; warm water becomes more easily saturated with oxygen, and the oxygen holding capacity reduces (Schaefer and Hollibaugh, 2017). Further, low DO in warm streams can also be contributed by high microbial activities (e.g., respiration) and degradation of organic matter (Mulholland et al., 1997; Hsiao et al., 2014). In this study, most streams did not show any notable linkage between solar radiation (SR) and stream DO. However, the effect of SR may be indirectly reflected by water temperature (TW), because SR is the principal energy source that causes stream heating. Further, the effect of SR is typically more clearly reflected in the diurnal cycle of stream DO (Abdul-Aziz and Ishtiaq, 2014), whereas datasets in this study represented monthly and seasonal samples. The impact of atmospheric pressure on stream DO was also not notable in this analysis, because data of AP did include much variation during the multi-year study period. Further, there was also a weak linkage of stream DO with nutrients in this region. Especially, TN had a very 
linkage with stream DO. Instead, TP had a noteworthy negative linkage with stream DO. This may be linked to the role of TP as the limiting nutrient in coastal streams (Dodds, 2006). High TP could potentially stimulate phytoplankton growth, which typically leads to higher organic matter, increased microbial respiration and decomposition, and a reduction in stream DO (Ice, 2008; Wang et al., 2014).

Streams located in the southern part of Texas and Florida showed a dominant $\mathrm{pH}$ control on stream DO. In this region, temperature of water were always high and relative less variable, and therefore the impact of TW was not as strong as that of the northern Gulf states. The reduced linkage of TW and DO could also be caused by excessive sunlight (i.e., photo inhibition; see Demmig-Adams and Adams lii, 1992) in this region. Instead, the notable positive linkages of $\mathrm{pH}$ with DO might have shown the effect of aquatic plant's photosynthesis on stream DO. During photosynthesis, stream plants absorb carbon dioxide and release oxygen, ultimately increasing the pH (i.e., decreasing $\mathrm{CO}_{2}$ ) of the stream (Bowmer and Muirhead, 1987; Petersen et al., 2001; Haag and Westrich, 2002). Moreover, warm water can have a high $\mathrm{pH}$ due to the conversion of $\mathrm{CO}_{2}$ to organic carbon by plant photosynthesis (King, 1970). The notable positive linkages of stream specific conductivity (SC) with DO indicated that a high salinity (represented by SC) can hinder the proliferation of algal blooms and eutrophication in coastal streams.

Streams in the transition region of the Gulf Coast showed controls of multiple drivers (i.e., stream flow, water temperature, and specific conductance) on stream DO. This region is located between $27^{\circ} 00^{\prime} 00^{\prime \prime} \mathrm{N}$ and $29^{\circ} 00^{\prime} 00^{\prime \prime} \mathrm{N}$ latitudes, which represents cold winters similar to the upper part of U.S.A and hot summer similar to the equatorial area. The two contrasting climate patterns, in concert with a complex mix of developed (e.g., urban, agriculture) and undeveloped (wetlands, open spaces) land uses, might have led to the mixed controls of stream DO in this "transitional" 
region. Flow rate (Q) had a strong negative linkage with DO. Factor analysis (Table 3) showed that flow rate $(\mathrm{Q})$ and total phosphorus $(\mathrm{TP})$ loaded highly on factor 1, suggesting that flow rate might have brought total phosphorus from agriculture area or urban sewage (Petersen et al., 2001; Banner et al., 2009). The maximum extent of hypoxia in the Gulf of Mexico is due to the high flow rate, which increases the density of stratification and eutrophication (Mulholland et al., 1997). Drewry et al. (2009) also found a positive correlation between discharging stream flow and TP of an estuary in Australia. Higher algal growth with increasing TP and a subsequent decomposition of organic matter might have consumed the available stream DO. In addition, Kennicutt (2017) found a high concentration of dissolved inorganic phosphorus in Tampa Bay due to the natural occurrence of phosphate rocks and anthropogenic activities in the draining watershed. Some streams in the "transition" region showed a strong negative linkage of specific conductance and DO. As salinity (SC) increases, the solubility of DO reduces, and stress for plant's photosynthesis increases (Pezeshki et al., 1989; Rietz and Haynes, 2003; Timpano et al., 2015). Datta and Sharma (1990) found that chlorophyll a content of leaves reduces under saline condition. The remaining streams in this region showed that water temperature had moderate to strong negative linkage with stream DO.

The estimated relative linkages can be used in identifying of management plans and targets to achieve a health stream ecosystem along the U.S. Gulf Coast and beyond. Since the climate components are the most dominant driver of DO in most streams (Figure 7A), restoration strategies and management activities should be designed to counteract the rapid change in atmospheric temperature. For example, riparian vegetation should be preserved or planted along the streams to increase shading and mitigate excessive warming of streams through solar radiation. Moreover, stream temperature is also affected by urban heat island effect, which could be mitigated by 
decreasing imperviousness and increasing green developments in the draining watersheds. The flow rate is the main contributor of in-stream nutrients, a major reduction of nutrients can be achieved by adding engineering solutions (e.g., detention ponds) and implementing best management practices.

\subsection{Conclusions}

The temporal relative linkages of stream dissolved oxygen with the dynamic environmental drivers were reliably estimated across the U.S. Gulf Coast by resolving multicollinearity through a systematic data analytics approach. Based on findings, streams were grouped into three regions across the U.S. Gulf Coast. In the northern part of Gulf Coast states (Texas, Louisiana, Mississippi, Alabama, and West Florida), water temperatures had the strongest and dictated control on stream DO. However, in the southern part of Texas and Florida coasts, $\mathrm{pH}$ showed the most dominant control on stream DO. Further, streams in between these two regions demonstrated notable controls of multiple drivers (water temperature, stream flow, and specific conductance) on DO. Four dynamic process components adequately described the system data variance in all three regions along the Gulf Coast. For example, the 'climate component' (temperature, solar radiation) in the northern part of Gulf Coast showed 2.7, 3.1, and 3.6 times stronger linkages with stream DO than that of the redox ( $\mathrm{pH}$, specific conductance), nutrient (total nitrogen, total phosphorus), and hydro-atmospheric (flow rate, atmospheric pressure) components, respectively. In contrast, in the southern part of Gulf Coast region, the redox components showed 1.6, 2.3, and 2.6 times stronger linkages with stream DO than that of the climate, nutrient, and hydro-atmospheric components, respectively. The identified environmental regimes and estimated linkages of stream DO provided important information into the dominant drivers and dynamic process components of water quality 
in urban/natural streams across the U.S. Gulf Coast. The knowledge and insights would help coastal managers and stakeholders to achieve a good stream water quality and ecosystem health. 


\section{REFERENCES}

Abdul-Aziz, O. I., and K. S. Ishtiaq (2014), Robust empirical modeling of dissolved oxygen in small rivers and streams: Scaling by a single reference observation, Journal of Hydrology, 511, 648-657.

Abdul-Aziz, O. I., and S. Ahmed (2017), Relative linkages of stream water quality and environmental health with the land use and hydrologic drivers in the coastal-urban watersheds of southeast Florida, GeoHealth, 1(4), 180-195.

Aggarwal, C. C., and P. S. Yu (2001), Outlier detection for high dimensional data, SIGMOD Record, 30(2), 37-46.

Akaike, H. (1974), A new look at the statistical model identification, IEEE Transactions on Automatic Control, 19(6), 716-723.

Ashurst, P. R., and M. J. Dennis (1998), Analytical Methods of Food Authentication, Springer Science and Business Media.

Banner, E. B. K., A. J. Stahl, and W. K. Dodds (2009), Stream discharge and riparian land use influence in-stream concentrations and loads of phosphorus from central plains watersheds, Environmental Management, 44(3), 552-565.

Basnyat, P., L. D. Teeter, K. M. Flynn, and B. G. Lockaby (1999), Relationships between landscape characteristics and nonpoint source pollution inputs to coastal estuaries, Environmental Management, 23(4), 539-549.

Bayram, A., E. Uzlu, M. Kankal, and T. Dede (2015), Modeling stream dissolved oxygen concentration using teaching-learning based optimization algorithm, Environmental Earth Sciences, 73(10), 6565-6576.

Bowmer, K. H., and W. A. Muirhead (1987), Inhibition of algal photosynthesis to control $\mathrm{pH}$ and reduce ammonia volatilization from rice floodwater, Fertilizer Research, 13(1), 13-29.

Box, G. E. P., and D. R. Cox (1964), An analysis of transformations, Journal of the Royal Statistical Society, 26(2), 211-252.

Bricker, S. B., B. Longstaff, W. Dennison, A. Jones, K. Boicourt, C. Wicks, and J. Woerner (2008), Effects of nutrient enrichment in the nation's estuaries: A decade of change, Harmful Algae, 8(1), 21-32.

Carrascal, L. M., I. Galván, and O. Gordo (2009), Partial least squares regression as an alternative to current regression methods used in ecology, Oikos, 118(5), 681-690.

Chambers, P. A., J. M. Culp, N. E. Glozier, K. J. Cash, F. J. Wrona, and L. Noton (2006), Northern rivers ecosystem initiative: Nutrients and dissolved oxygen - issues and impacts, Environmental Monitoring and Assessment, 113(1), 117-141. 
Chelsea Nagy, R., B. Graeme Lockaby, L. Kalin, and C. Anderson (2012), Effects of urbanization on stream hydrology and water quality: The Florida gulf coast, Hydrological Processes, 26(13), 2019-2030.

Datta, K. S., and K. D. Sharma (1990), Effect of chloride and sulphate types of salinity on characteristics of chlorophyll content, photosynthesis and respiration of chickpea (Cicer arietinum L.), Biologia Plantarum, 32(5), 391-395.

de Jong, S. (1993), SIMPLS: An alternative approach to partial least squares regression, Chemometrics and Intelligent Laboratory Systems, 18(3), 251-263.

Demmig-Adams, B., and W. Adams Iii (1992), Photoprotection and other responses of plants to high light stress, Annual Review of Plant Physiology and Plant Molecular Biology, 43, 599-626.

Devarakonda, N., S. Subhani, and S. A. H. Basha (2014), Outliers detection in regression analysis using partial least square approach, in ICT and Critical Infrastructure: Proceedings of the 48th Annual Convention of Computer Society of India- Vol II: Hosted by CSI Vishakapatnam Chapter, edited by S. C. Satapathy, P. S. Avadhani, S. K. Udgata and S. Lakshminarayana, Springer International Publishing.

DiDonato, G. T., J. R. Stewart, D. M. Sanger, B. J. Robinson, B. C. Thompson, A. F. Holland, and R. F. Van Dolah (2009), Effects of changing land use on the microbial water quality of tidal creeks, Marine Pollution Bulletin, 58(1), 97-106.

Dodds, W. K. (2006), Nutrients and the "dead zone": The link between nutrient ratios and dissolved oxygen in the northern Gulf of Mexico, Frontiers in Ecology and the Environment, 4(4), 211-217.

Drewry, J. J., L. T. H. Newham, and B. F. W. Croke (2009), Suspended sediment, nitrogen and phosphorus concentrations and exports during storm-events to the Tuross estuary, Australia, Journal of Environmental Management, 90(2), 879-887.

Haag, I., and B. Westrich (2002), Processes governing river water quality identified by principal component analysis, Hydrological Processes, 16(16), 3113-3130.

Helena, B., R. Pardo, M. Vega, E. Barrado, J. M. Fernandez, and L. Fernandez (2000), Temporal evolution of groundwater composition in an alluvial aquifer (Pisuerga River, Spain) by principal component analysis, Water Research, 34(3), 807-816.

Hsiao, S. Y., T. C. Hsu, J. W. Liu, X. Xie, Y. Zhang, J. Lin, H. Wang, J. Y. Yang, S. C. Hsu, and M. Dai (2014), Nitrification and its oxygen consumption along the turbid Chang Jiang River plume, Biogeosciences, 11(5), 2083-2098.

Ice, G. G. (2008), Stream temperature and dissolved oxygen, in Hydrological and Biological Responses to Forest Practices: The Alsea watershed study, edited by J. D. Stednick, Springer, New York.

Ishtiaq, K. S., and O. I. Abdul-Aziz (2015), Relative linkages of canopy-level CO2 fluxes with the climatic and environmental variables for us deciduous forests, Environmental Management, 55(4), 943-960. 
Johnson, R.A., and D.W. Wichern (1992), Applied Multivariate Statistical Analysis. Prentice-Hall, Englewood Cliffs, NJ.

Jolliffe, I. T. (2002), Principal Component Analysis, 2nd ed., Springer, New York.

Kannel, P. R., S. R. Kanel, S. Lee, Y. S. Lee, and T. Y. Gan (2011), A review of public domain water quality models for simulating dissolved oxygen in rivers and streams, Environmental Modeling and Assessment, 16(2), 183-204.

Kazi, T. G., M. B. Arain, M. K. Jamali, N. Jalbani, H. I. Afridi, R. A. Sarfraz, J. A. Baig, and A. Q. Shah (2009), Assessment of water quality of polluted lake using multivariate statistical techniques: A case study, Ecotoxicology and Environmental Safety, 72(2), 301-309.

Kennicutt, M. C. (2017), Water Quality of the Gulf of Mexico, in Habitats and Biota of the Gulf of Mexico: Before the Deepwater Horizon Oil Spill: Volume 1: Water Quality, Sediments, Sediment Contaminants, Oil and Gas Seeps, Coastal Habitats, Offshore Plankton and Benthos, and Shellfish, edited by C. H. Ward, Springer, New York.

Kim, J. H., R. H. Kim, J. Lee, T. J. Cheong, B. W. Yum, and H. W. Chang (2005), Multivariate statistical analysis to identify the major factors governing groundwater quality in the coastal area of Kimje, South Korea, Hydrological Processes, 19(6), 1261-1276.

King, D. L. (1970), The role of carbon in eutrophication, Journal of the Water Pollution Control Federation, 42(12), 2035-2051.

Kuhn, M., and K. Johnson (2013), Applied Predictive Modeling, Springer, New York.

Kuppusamy, M., and V. Giridhar (2006), Factor analysis of water quality characteristics including trace metal speciation in the coastal environmental system of Chennai Ennore, Environment International, 32(2), 174-179.

Li, X., P. Li, D. Wang, and Y. Wang (2014), Assessment of temporal and spatial variations in water quality using multivariate statistical methods: A case study of the Xin'anjiang River, China, Frontiers of Environmental Science and Engineering, 8(6), 895-904.

Meglen, R. R. (1992), Examining large databases: A chemometric approach using principal component analysis, Marine Chemistry, 39(1), 217-237.

Mulholland, P. J., G. R. Best, C. C. Coutant, G. M. Hornberger, J. L. Meyer, P. J. Robinson, J. R. Stenberg, R. E. Turner, F. Vera-Herrera, and R. G. Wetzel (1997), Effects of climate change on freshwater ecosystems of the south-eastern United States and the Gulf Coast of Mexico, Hydrological Processes, 11(8), 949-970.

National Solar Radiation Data Base (NSRDB) (2017), Available online at http://rredc.nrel.gov/solar/old_data/nsrdb/ (Accessed on January 01, 2017).

Petersen, W., L. Bertino, U. Callies, and E. Zorita (2001), Process identification by principal component analysis of river water-quality data, Ecological Modelling, 138(1), 193-213.

Pezeshki, S. R., R. D. DeLaune, and W. H. Patrick (1989), Assessment of saltwater intrusion impact on gas exchange behavior of Louisiana Gulf Coast wetland species, Wetlands Ecology and Management, 1(1), 21-30. 
Rabalais, N. N., R. E. Turner, D. JustiĆ, Q. Dortch, W. J. Wiseman, and B. K. Sen Gupta (1996), Nutrient changes in the Mississippi River and system responses on the adjacent continental shelf, Estuaries, 19(2), 386-407.

Rietz, D. N., and R. J. Haynes (2003), Effects of irrigation-induced salinity and sodicity on soil microbial activity, Soil Biology and Biochemistry, 35(6), 845-854.

Santhi, C., R. Srinivasan, J. G. Arnold, and J. R. Williams (2006), A modeling approach to evaluate the impacts of water quality management plans implemented in a watershed in Texas, Environmental Modelling and Software, 21(8), 1141-1157.

Schaefer, S. C., and J. T. Hollibaugh (2017), Temperature decouples ammonium and nitrite oxidation in coastal waters, Environmental Science and Technology, 51(6), 3157-3164.

Shrestha, S., and F. Kazama (2007), Assessment of surface water quality using multivariate statistical techniques: A case study of the Fuji river basin, Japan, Environmental Modelling and Software, 22(4), 464-475.

Timpano, A. J., S. H. Schoenholtz, D. J. Soucek, and C. E. Zipper (2015), Salinity as a limiting factor for biological condition in mining-influenced central Appalachian headwater streams, Journal of the American Water Resources Association, 51(1), 240-250.

Turner, R. E., N. N. Rabalais, R. B. Alexander, G. Mcisaac, and R. W. Howarth (2007), Characterization of nutrient, organic carbon, and sediment loads and concentrations from the Mississippi River into the northern Gulf of Mexico, Estuaries Coasts, 30(5), 773-790.

United States Geological Survey (USGS) (2017), Available online at https://www.waterqualitydata.us/ (Accessed on January 01, 2017).

Vega, M., R. Pardo, E. Barrado, and L. Debán (1998), Assessment of seasonal and polluting effects on the quality of river water by exploratory data analysis, Water Research, 32(12), 3581-3592.

Wang, Z. Y., J. H. W. Lee, and C.S. Melching (2014), River Dynamics and Integrated River Management, Springer Verlag and Tsinghua Press, Berlin/Beijing.

Wold, S., J. Jonsson, M. Sjörström, M. Sandberg, and S. Rännar (1993), DNA and peptide sequences and chemical processes multivariately modelled by principal component analysis and partial least-squares projections to latent structures, Analytica Chimica Acta, 277(2), 239-253.

Wold, S., M. Sjöström, and L. Eriksson (2001), PLS-regression: A basic tool of chemometrics, Chemometrics and Intelligent Laboratory Systems, 58(2), 109-130. 


\section{APPENDIX A}

Table A1: Correlation coefficients of stream DO with the dynamic environmental predictors for the selected water quality monitoring stations along the U.S. Gulf Coast.

\begin{tabular}{|c|c|c|c|c|c|c|c|c|c|}
\hline Station & I & TN & $\mathrm{TP}$ & $\mathrm{SC}$ & $\mathrm{pH}$ & $\mathrm{Q}$ & AP & TW & SR \\
\hline USGS-08475000 & TX_1 & 0.17 & -0.06 & 0.26 & 0.51 & -0.11 & 0.10 & -0.54 & -0.13 \\
\hline USGS-08459200 & TX_2 & 0.20 & 0.05 & 0.29 & 0.36 & -0.13 & 0.22 & -0.76 & -0.35 \\
\hline USGS-08042554 & TX_3 & 0.22 & -0.28 & 0.19 & 0.64 & -0.13 & 0.37 & -0.79 & -0.24 \\
\hline USGS-08042546 & TX_4 & 0.27 & 0.03 & 0.12 & 0.07 & 0.01 & -0.11 & -0.76 & -0.36 \\
\hline USGS-08116650 & TX_5 & 0.18 & 0.11 & 0.26 & 0.25 & -0.21 & 0.16 & -0.49 & -0.01 \\
\hline USGS-08070200 & TX_6 & -0.21 & -0.42 & 0.07 & 0.10 & 0.31 & 0.42 & -0.90 & -0.28 \\
\hline USGS-08012150 & LS_1 & -0.22 & -0.18 & -0.46 & -0.25 & 0.32 & 0.14 & -0.71 & 0.07 \\
\hline USGS-08014500 & LS_2 & 0.00 & -0.34 & 0.01 & 0.06 & -0.01 & 0.36 & -0.68 & -0.26 \\
\hline USGS-07381590 & LS_3 & 0.01 & -0.10 & -0.09 & 0.33 & -0.15 & 0.34 & -0.85 & -0.35 \\
\hline USGS-07381495 & LS_4 & -0.12 & -0.08 & -0.15 & 0.18 & -0.09 & 0.38 & -0.84 & -0.32 \\
\hline USGS-07381600 & LS_5 & 0.06 & -0.08 & -0.01 & 0.38 & -0.23 & 0.35 & -0.82 & -0.36 \\
\hline USGS-07373420 & LS_6 & -0.20 & -0.07 & -0.09 & 0.15 & -0.09 & 0.32 & -0.87 & -0.41 \\
\hline USGS-07374000 & LS_7 & -0.08 & -0.02 & -0.10 & 0.42 & -0.05 & 0.24 & -0.90 & -0.34 \\
\hline USGS-07374525 & LS_8 & -0.03 & 0.11 & -0.11 & 0.33 & -0.03 & 0.45 & -0.91 & -0.21 \\
\hline USGS-02470500 & AL_1 & 0.05 & -0.14 & 0.12 & 0.38 & -0.12 & 0.26 & -0.62 & -0.16 \\
\hline USGS-02469762 & AL_2 & 0.33 & 0.29 & -0.21 & -0.23 & 0.27 & 0.38 & -0.86 & -0.39 \\
\hline USGS-02429500 & AL_3 & 0.23 & -0.09 & -0.03 & -0.33 & 0.21 & 0.15 & -0.85 & -0.32 \\
\hline 21AWIC-7870 & AL_4 & -0.18 & -0.17 & -0.06 & 0.50 & -0.15 & 0.27 & -0.94 & -0.19 \\
\hline
\end{tabular}

Note: (1) TX, LS, and AL, respectively, refers to stations in Texas, Louisiana, and Alabama. (2) * STORET water quality station. (3) Bold value indicates moderate to strong correlation. (4) "I" is station identifier. 
Table A1 (continued): Correlation result of predictors with stream DO for each water quality monitoring stations across the Gulf Coast.

\begin{tabular}{lccccccccc}
\hline Station & I & TN & TP & SC & pH & Q & AP & TW & SR \\
\hline USGS-02359170 & FL_1 & 0.28 & -0.29 & 0.02 & -0.23 & 0.06 & 0.30 & $\mathbf{- 0 . 6 6}$ & -0.36 \\
USGS-02312600 & FL_2 & $\mathbf{- 0 . 4 3}$ & $\mathbf{- 0 . 5 7}$ & 0.19 & 0.04 & -0.09 & 0.33 & $\mathbf{- 0 . 6 7}$ & -0.32 \\
USGS-02312500 & FL_3 & $\mathbf{- 0 . 5 7}$ & $\mathbf{- 0 . 6 5}$ & $\mathbf{0 . 6 3}$ & $\mathbf{0 . 5 4}$ & $\mathbf{- 0 . 5 1}$ & $\mathbf{0 . 5 6}$ & $\mathbf{- 0 . 6 1}$ & -0.05 \\
USGS-02310947 & FL_4 & -0.34 & 0.05 & $\mathbf{- 0 . 6 4}$ & -0.35 & $\mathbf{0 . 4 8}$ & 0.13 & -0.11 & 0.09 \\
USGS-02310300 & FL_5 & 0.13 & $\mathbf{- 0 . 6 0}$ & $\mathbf{0 . 4 1}$ & $\mathbf{0 . 4 9}$ & $\mathbf{- 0 . 7 5}$ & 0.32 & $\mathbf{- 0 . 4 8}$ & -0.06 \\
USGS-02303000 & FL_6 & $\mathbf{0 . 4 3}$ & $\mathbf{- 0 . 7 6}$ & $\mathbf{0 . 6 8}$ & 0.10 & $\mathbf{- 0 . 6 2}$ & $\mathbf{0 . 6 8}$ & $\mathbf{- 0 . 8 7}$ & -0.36 \\
USGS-02309445 & FL_7 & $\mathbf{- 0 . 4 2}$ & $\mathbf{- 0 . 4 1}$ & 0.19 & -0.12 & -0.08 & 0.13 & $\mathbf{- 0 . 5 4}$ & 0.05 \\
USGS-02309425 & FL_8 & 0.25 & -0.34 & 0.40 & 0.00 & -0.23 & 0.35 & $\mathbf{- 0 . 7 1}$ & -0.28 \\
USGS-02307671 & FL_9 & -0.28 & -0.35 & -0.12 & 0.06 & 0.20 & 0.10 & $\mathbf{- 0 . 5 9}$ & -0.07 \\
USGS-02307731 & FL_10 & -0.07 & $\mathbf{- 0 . 4 4}$ & 0.11 & -0.03 & 0.05 & 0.21 & $\mathbf{- 0 . 7 6}$ & -0.10 \\
USGS-02301300 & FL_11 & 0.16 & $\mathbf{- 0 . 5 5}$ & $\mathbf{- 0 . 8 2}$ & $\mathbf{- 0 . 6 3}$ & $\mathbf{0 . 6 9}$ & $\mathbf{0 . 5 3}$ & $\mathbf{- 0 . 6 9}$ & -0.33 \\
USGS-02300100 & FL_12 & -0.37 & $\mathbf{- 0 . 4 1}$ & -0.11 & 0.08 & -0.37 & $\mathbf{0 . 4 2}$ & $\mathbf{- 0 . 8 0}$ & 0.02 \\
USGS-02295420 & FL_13 & -0.20 & -0.11 & 0.23 & $\mathbf{0 . 4 3}$ & -0.24 & $\mathbf{0 . 5 7}$ & $\mathbf{- 0 . 8 8}$ & 0.00 \\
USGS-02296750 & FL_14 & -0.32 & -0.18 & 0.25 & 0.36 & -0.29 & 0.29 & $\mathbf{- 0 . 5 4}$ & -0.34 \\
USGS-02298123 & FL_15 & -0.26 & $\mathbf{- 0 . 7 1}$ & 0.10 & 0.22 & $\mathbf{- 0 . 4 2}$ & $\mathbf{0 . 5 0}$ & $\mathbf{- 0 . 8 6}$ & -0.38 \\
21FLEECO_WQX & FL_16 & -0.22 & $\mathbf{- 0 . 4 2}$ & 0.29 & $\mathbf{0 . 6 4}$ & -0.33 & $\mathbf{0 . 5 9}$ & $\mathbf{- 0 . 5 3}$ & -0.34 \\
21FLEECO_WQX & FL_17 & $\mathbf{0 . 4 1}$ & -0.30 & $\mathbf{- 0 . 4 7}$ & $\mathbf{0 . 4 3}$ & 0.26 & 0.21 & $\mathbf{- 0 . 5 1}$ & -0.20 \\
21FLEECO_WQX & FL_18 & 0.05 & 0.00 & -0.14 & $\mathbf{0 . 7 0}$ & -0.31 & 0.19 & $\mathbf{- 0 . 4 1}$ & 0.08 \\
\hline NFI(1)
\end{tabular}

Note: (1) FL refers stations in Florida. (2) *21FLEECO STORET water quality station. (3) Bold value indicates moderate to strong correlation. (4) "I" is station identifier. 
Table A2: Ensemble mean triangular matrices and mutual correlation of the dynamic environmental drivers for the TW dominated regime.

\begin{tabular}{lccccccccc}
\hline & TN & TP & TW & SC & pH & Q & AP & SR & DO \\
\hline TN & 1.00 & 0.35 & -0.03 & 0.00 & -0.10 & 0.13 & -0.03 & -0.02 & -0.03 \\
TP & 0.35 & 1.00 & 0.14 & -0.14 & -0.13 & 0.22 & -0.07 & 0.07 & -0.23 \\
TW & -0.03 & 0.14 & 1.00 & 0.08 & 0.00 & -0.06 & -0.45 & 0.28 & $\mathbf{- 0 . 7 5}$ \\
SC & 0.00 & -0.14 & 0.08 & 1.00 & 0.39 & $\mathbf{- 0 . 5 7}$ & 0.11 & 0.02 & 0.06 \\
pH & -0.10 & -0.13 & 0.00 & 0.39 & 1.00 & -0.34 & 0.12 & 0.00 & 0.17 \\
Q & 0.13 & 0.22 & -0.06 & $\mathbf{- 0 . 5 7}$ & -0.34 & 1.00 & -0.14 & -0.01 & -0.08 \\
AP & -0.03 & -0.07 & -0.45 & 0.11 & 0.12 & -0.14 & 1.00 & -0.05 & 0.31 \\
SR & -0.02 & 0.07 & 0.28 & 0.02 & 0.00 & -0.01 & -0.05 & 1.00 & -0.23 \\
DO & -0.03 & -0.23 & $\mathbf{- 0 . 7 5}$ & 0.06 & 0.17 & -0.08 & 0.31 & -0.23 & 1.00 \\
\hline
\end{tabular}

Note: (1) TN, TP, SC, pH, Q, AP, TW, SR and DO respectively, refer to total nitrogen, total phosphorus, specific conductance, potential of hydrogen, stream flow, atmospheric pressure, water temperature, solar radiation, dissolved oxygen.

Table A3: Triangular matrices and mutual correlation of the dynamic environmental drivers for the $\mathrm{Q}$ dominated regime.

\begin{tabular}{lccccccccc}
\hline & $\mathrm{TN}$ & $\mathrm{TP}$ & $\mathrm{TW}$ & $\mathrm{SC}$ & $\mathrm{pH}$ & $\mathrm{Q}$ & $\mathrm{AP}$ & $\mathrm{SR}$ & $\mathrm{DO}$ \\
\hline TN & 1.00 & -0.26 & 0.12 & -0.21 & 0.31 & -0.41 & 0.03 & 0.18 & 0.13 \\
TP & -0.26 & 1.00 & 0.35 & -0.20 & -0.38 & $\mathbf{0 . 5 0}$ & -0.46 & 0.13 & -0.60 \\
TW & 0.12 & 0.35 & 1.00 & -0.23 & 0.10 & -0.11 & $\mathbf{- 0 . 6 3}$ & 0.36 & -0.48 \\
SC & -0.21 & -0.20 & -0.23 & 1.00 & -0.09 & -0.25 & 0.32 & -0.26 & 0.41 \\
pH & 0.31 & -0.38 & 0.10 & -0.09 & 1.00 & $\mathbf{- 0 . 6 3}$ & -0.05 & 0.30 & 0.49 \\
Q & -0.41 & $\mathbf{0 . 5 0}$ & -0.11 & -0.25 & $\mathbf{- 0 . 6 3}$ & 1.00 & -0.01 & -0.23 & $\mathbf{- 0 . 7 5}$ \\
AP & 0.03 & -0.46 & $\mathbf{- 0 . 6 3}$ & 0.32 & -0.05 & -0.01 & 1.00 & -0.46 & 0.32 \\
SR & 0.18 & 0.13 & 0.36 & -0.26 & 0.30 & -0.23 & -0.46 & 1.00 & -0.06 \\
DO & 0.13 & -0.60 & -0.48 & 0.41 & 0.49 & $\mathbf{- 0 . 7 5}$ & 0.32 & -0.06 & 1.00 \\
\hline
\end{tabular}

Note: (1) TN, TP, SC, pH, Q, AP, TW, SR and DO respectively, refer to total nitrogen, total phosphorus, specific conductance, potential of hydrogen, stream flow, atmospheric pressure, water temperature, solar radiation, dissolved oxygen. 
Table A4: Ensemble mean triangular matrices and mutual correlation of the dynamic environmental drivers for the SC dominated regime.

\begin{tabular}{lccccccccc}
\hline & TN & TP & TW & SC & pH & Q & AP & SR & DO \\
\hline TN & 1.00 & -0.05 & 0.10 & 0.14 & 0.32 & 0.03 & 0.06 & -0.23 & -0.09 \\
TP & -0.05 & 1.00 & $\mathbf{0 . 5 9}$ & -0.01 & 0.02 & -0.02 & -0.33 & 0.41 & -0.25 \\
TW & 0.10 & $\mathbf{0 . 5 9}$ & 1.00 & 0.20 & 0.35 & 0.05 & -0.43 & 0.22 & -0.40 \\
SC & 0.14 & -0.01 & 0.20 & 1.00 & $\mathbf{0 . 5 8}$ & $\mathbf{- 0 . 8 0}$ & -0.07 & -0.01 & $-\mathbf{0 . 7 3}$ \\
pH & 0.32 & 0.02 & 0.35 & $\mathbf{0 . 5 8}$ & 1.00 & -0.38 & -0.25 & 0.14 & -0.49 \\
Q & 0.03 & -0.02 & 0.05 & $\mathbf{- 0 . 8 0}$ & -0.38 & 1.00 & 0.11 & -0.05 & $\mathbf{0 . 5 8}$ \\
AP & 0.06 & -0.33 & -0.43 & -0.07 & -0.25 & 0.11 & 1.00 & -0.01 & 0.33 \\
SR & -0.23 & 0.41 & 0.22 & -0.01 & 0.14 & -0.05 & -0.01 & 1.00 & -0.12 \\
DO & -0.09 & -0.25 & -0.40 & $\mathbf{- 0 . 7 3}$ & -0.49 & $\mathbf{0 . 5 8}$ & 0.33 & -0.12 & 1.00 \\
\hline
\end{tabular}

Note: (1) TN, TP, SC, pH, Q, AP, TW, SR and DO respectively, refer to total nitrogen, total phosphorus, specific conductance, potential of hydrogen, stream flow, atmospheric pressure, water temperature, solar radiation, dissolved oxygen.

Table A5: Ensemble mean triangular matrices and mutual correlation of the dynamic environmental drivers for the $\mathrm{pH}$ dominated regime.

\begin{tabular}{lccccccccc}
\hline & TN & TP & TW & SC & $\mathrm{pH}$ & $\mathrm{Q}$ & $\mathrm{AP}$ & $\mathrm{SR}$ & $\mathrm{DO}$ \\
\hline TN & 1.00 & 0.23 & -0.34 & 0.04 & -0.03 & 0.10 & 0.09 & -0.12 & 0.00 \\
TP & 0.23 & 1.00 & -0.06 & -0.09 & -0.19 & 0.19 & -0.10 & -0.18 & -0.16 \\
TW & -0.34 & -0.06 & 1.00 & -0.04 & -0.25 & 0.17 & $\mathbf{- 0 . 5 3}$ & 0.36 & -0.49 \\
SC & 0.04 & -0.09 & -0.04 & 1.00 & -0.04 & -0.07 & -0.01 & -0.07 & 0.14 \\
pH & -0.03 & -0.19 & -0.25 & -0.04 & 1.00 & -0.33 & 0.20 & -0.08 & $\mathbf{0 . 6 2}$ \\
Q & 0.10 & 0.19 & 0.17 & -0.07 & -0.33 & 1.00 & -0.21 & 0.03 & -0.25 \\
AP & 0.09 & -0.10 & $\mathbf{- 0 . 5 3}$ & -0.01 & 0.20 & -0.21 & 1.00 & -0.29 & 0.29 \\
SR & -0.12 & -0.18 & 0.36 & -0.07 & -0.08 & 0.03 & -0.29 & 1.00 & -0.13 \\
DO & 0.00 & -0.16 & -0.49 & 0.14 & $\mathbf{0 . 6 2}$ & -0.25 & 0.29 & -0.13 & 1.00
\end{tabular}

Note: (1) TN, TP, SC, pH, Q, AP, TW, SR and DO respectively, refer to total nitrogen, total phosphorus, specific conductance, potential of hydrogen, stream flow, atmospheric pressure, water temperature, solar radiation, dissolved oxygen. 
Table A6: Percent variance explained by each principal components (PC) for each water quality monitoring stations along the Gulf Coast states.

\begin{tabular}{lccccccccc}
\hline Stations & I & PC1 & PC2 & PC3 & PC4 & PC5 & PC6 & PC7 & PC8 \\
\hline USGS-08475000 & TX_1 & 26.51 & 20.08 & 13.65 & 11.84 & 8.43 & 6.66 & 5.72 & 4.64 \\
USGS-08459200 & TX_2 & 30.27 & 24.05 & 11.60 & 10.42 & 8.24 & 6.32 & 5.45 & 2.00 \\
USGS-08042554 & TX_3 & 35.28 & 29.64 & 9.59 & 8.45 & 5.62 & 4.62 & 4.28 & 1.73 \\
USGS-08042546 & TX_4 & 48.69 & 23.00 & 14.85 & 5.12 & 4.57 & 1.55 & 1.26 & 0.75 \\
USGS-08116650 & TX_5 & 42.42 & 20.59 & 12.88 & 10.59 & 7.77 & 3.04 & 1.64 & 0.72 \\
USGS-08070200 & TX_6 & 32.62 & 18.70 & 15.95 & 10.92 & 7.38 & 6.08 & 4.67 & 2.69 \\
USGS-08012150 & LA_1 & 40.84 & 16.83 & 16.20 & 10.75 & 7.30 & 3.87 & 2.18 & 1.68 \\
USGS-08014500 & LA_2 & 36.07 & 22.40 & 14.96 & 10.16 & 6.14 & 5.13 & 2.76 & 1.63 \\
USGS-07381590 & LA_3 & 28.61 & 25.81 & 14.33 & 9.48 & 8.62 & 5.86 & 4.12 & 2.62 \\
USGS-07381495 & LA_4 & 28.82 & 23.59 & 14.84 & 9.74 & 7.45 & 7.01 & 5.35 & 2.35 \\
USGS-07381600 & LA_5 & 27.24 & 26.68 & 15.37 & 9.32 & 8.20 & 5.17 & 4.36 & 3.00 \\
USGS-07373420 & LA_6 & 27.95 & 23.40 & 13.79 & 10.98 & 8.65 & 7.01 & 5.67 & 1.76 \\
USGS-07374000 & LA_7 & 27.07 & 25.86 & 14.75 & 10.68 & 8.82 & 5.91 & 4.86 & 1.59 \\
USGS-07374525 & LA_8 & 30.47 & 26.72 & 12.93 & 10.51 & 7.41 & 5.86 & 4.21 & 1.48 \\
USGS-02470500 & AL_1 & 37.32 & 22.06 & 12.55 & 10.94 & 7.25 & 3.89 & 3.34 & 1.74 \\
USGS-02469762 & AL_2 & 45.09 & 20.90 & 10.32 & 6.98 & 6.00 & 5.39 & 3.01 & 1.45 \\
USGS-02429500 & AL_3 & 37.42 & 20.52 & 14.15 & 10.80 & 6.73 & 4.15 & 3.46 & 2.13 \\
$* 21 A W I C-7870$ & AL_4 & 32.78 & 18.19 & 15.20 & 12.30 & 7.18 & 6.39 & 5.99 & 1.55 \\
\hline Ne:(1) TX, LS, & AL_
\end{tabular}

Note: (1) TX, LS, and AL, respectively, refers to stations in Texas, Louisiana, and Alabama. (2) * STORET water quality station. (3) "I" is station identifier. 
Table A6 (continued): Percent variance explained by each principal components (PC) for each water quality monitoring stations along the Gulf Coast states.

\begin{tabular}{lccccccccc}
\hline Stations & I & PC1 & PC2 & PC3 & PC4 & PC5 & PC6 & PC7 & PC8 \\
\hline USGS-02359170 & FL_1 & 34.90 & 24.31 & 11.20 & 10.02 & 7.40 & 5.74 & 3.66 & 1.81 \\
USGS-02312600 & FL_2 & 40.77 & 20.55 & 15.52 & 7.69 & 6.54 & 4.76 & 2.58 & 1.19 \\
USGS-02312500 & FL_3 & 50.29 & 18.90 & 11.63 & 8.19 & 4.03 & 3.27 & 1.88 & 1.09 \\
USGS-02310947 & FL_4 & 34.60 & 23.00 & 13.25 & 8.90 & 6.78 & 5.27 & 4.29 & 2.84 \\
USGS-02301300 & FL_5 & 34.88 & 26.61 & 11.87 & 8.19 & 6.27 & 4.95 & 4.18 & 2.65 \\
USGS-02303000 & FL_6 & 49.57 & 15.99 & 12.06 & 7.75 & 7.31 & 3.41 & 2.15 & 1.31 \\
USGS-02309445 & FL_7 & 32.47 & 21.37 & 16.26 & 11.90 & 7.02 & 4.86 & 3.34 & 1.72 \\
USGS-02309425 & FL_8 & 37.72 & 14.58 & 12.21 & 10.26 & 7.81 & 6.69 & 5.24 & 3.53 \\
USGS-02307671 & FL_9 & 29.03 & 19.40 & 16.40 & 10.49 & 8.87 & 6.47 & 4.42 & 2.75 \\
USGS-02307731 & FL_10 & 31.02 & 21.19 & 14.67 & 13.11 & 7.29 & 5.15 & 3.91 & 2.48 \\
USGS-02310300 & FL_11 & 46.89 & 17.46 & 16.98 & 9.64 & 3.98 & 2.21 & 1.45 & 0.95 \\
USGS-02300100 & FL_12 & 33.73 & 20.64 & 13.17 & 8.95 & 8.42 & 6.83 & 4.23 & 2.93 \\
USGS-02295420 & FL_13 & 34.96 & 23.37 & 15.05 & 8.35 & 6.69 & 4.83 & 3.24 & 2.77 \\
USGS-02296750 & FL_14 & 36.18 & 24.44 & 14.52 & 9.62 & 6.90 & 3.70 & 2.55 & 1.57 \\
USGS-02298123 & FL_15 & 43.82 & 21.66 & 12.65 & 8.02 & 6.30 & 3.12 & 2.04 & 1.72 \\
*WQX-10MIGR10 & FL_16 & 27.47 & 21.46 & 14.43 & 11.31 & 8.58 & 7.08 & 5.12 & 3.77 \\
*WQX-10MIGR80 & FL_17 & 36.60 & 16.18 & 13.65 & 10.80 & 8.41 & 7.81 & 3.33 & 1.84 \\
*WQX-46B-9GR & FL_18 & 30.26 & 21.54 & 12.12 & 9.20 & 8.46 & 6.78 & 5.21 & 4.67 \\
\hline NW:(1)FL refs & & &
\end{tabular}

Note: (1) FL refers stations in Florida. (2) *21FLEECO STORET water quality station. (3) "I" is station identifier. 
Table A7: Representative factor analysis extracted from data matrices the four environmental regimes based on which DO loaded on different factor.

\begin{tabular}{|c|c|c|c|c|c|c|c|c|c|c|}
\hline Regimes & $\mathrm{F}$ & $\mathrm{TN}$ & $\mathrm{TP}$ & TW & $\mathrm{SC}$ & $\mathrm{pH}$ & $\mathrm{Q}$ & $\mathrm{BP}$ & SR & DO \\
\hline \multicolumn{11}{|c|}{ Northern Gulf Coast State (NGCS) } \\
\hline \multicolumn{11}{|c|}{ Temperature dominated stations } \\
\hline \multirow[t]{3}{*}{ Type I } & 1 & 0.35 & -0.02 & -0.95 & -0.04 & -0.24 & 0.27 & 0.20 & -0.43 & 0.91 \\
\hline & 2 & -0.35 & -0.09 & 0.16 & 0.88 & 0.45 & -0.69 & 0.32 & -0.16 & -0.02 \\
\hline & 3 & 0.70 & 0.81 & -0.24 & -0.10 & 0.05 & 0.46 & -0.30 & -0.24 & -0.11 \\
\hline \multirow[t]{3}{*}{ Type II } & 1 & 0.27 & 0.66 & -0.05 & -0.92 & -0.69 & 0.99 & -0.19 & 0.11 & -0.09 \\
\hline & 2 & 0.40 & 0.55 & 0.75 & -0.11 & -0.04 & -0.01 & -0.38 & 0.22 & -0.98 \\
\hline & 3 & 0.11 & -0.20 & -0.42 & -0.02 & 0.38 & 0.09 & 0.42 & 0.60 & -0.16 \\
\hline \multirow[t]{4}{*}{ Type III } & 1 & 0.61 & 0.95 & -0.26 & -0.36 & -0.21 & 0.60 & 0.09 & 0.01 & -0.11 \\
\hline & 2 & -0.02 & -0.28 & 0.22 & 0.63 & 0.92 & -0.59 & 0.07 & 0.01 & 0.36 \\
\hline & 3 & 0.20 & 0.08 & -0.94 & -0.02 & 0.01 & 0.24 & 0.36 & -0.33 & 0.78 \\
\hline & & Transiti & on Regi & of of th & e U.S. C & ulf $\mathrm{Co}$ & & & & \\
\hline \multicolumn{11}{|c|}{ Flow rate dominated stations } \\
\hline & 1 & 0.34 & -0.55 & -0.06 & 0.30 & 0.63 & -0.98 & 0.07 & 0.16 & 0.87 \\
\hline & 2 & -0.09 & 0.45 & 0.56 & -0.26 & 0.10 & -0.03 & -0.92 & 0.45 & -0.20 \\
\hline & 3 & 0.41 & 0.07 & 0.72 & -0.20 & 0.07 & -0.20 & -0.16 & 0.25 & -0.45 \\
\hline \multicolumn{11}{|c|}{ Specific conductance dominated stations } \\
\hline & 1 & 0.31 & -0.18 & -0.05 & 0.98 & 0.52 & -0.84 & 0.14 & 0.00 & -0.68 \\
\hline & 2 & -0.02 & 0.98 & 0.57 & -0.20 & -0.21 & 0.09 & -0.46 & 0.16 & -0.04 \\
\hline & 3 & -0.43 & -0.12 & -0.29 & 0.05 & -0.19 & -0.13 & 0.75 & 0.35 & 0.29 \\
\hline \multicolumn{11}{|c|}{ Southern Gulf Coast State (SGCS) } \\
\hline \multicolumn{11}{|c|}{ pH dominated stations } \\
\hline \multirow[t]{3}{*}{ Type I } & 1 & -0.09 & -0.06 & -0.30 & -0.37 & 0.96 & -0.50 & 0.18 & 0.19 & 0.73 \\
\hline & 2 & 0.23 & 0.00 & -0.50 & -0.09 & 0.24 & -0.03 & 0.98 & -0.24 & 0.05 \\
\hline & 3 & 0.55 & 0.62 & -0.34 & -0.14 & -0.11 & 0.06 & 0.04 & -0.44 & 0.15 \\
\hline \multirow[t]{3}{*}{ Type II } & 1 & -0.03 & 0.14 & 0.82 & 0.09 & -0.13 & 0.26 & -0.89 & 0.57 & -0.46 \\
\hline & 2 & -0.07 & -0.46 & -0.24 & 0.41 & 0.70 & -0.28 & 0.20 & -0.10 & 0.82 \\
\hline & 3 & 0.99 & -0.18 & -0.26 & -0.02 & 0.04 & -0.06 & -0.09 & 0.03 & -0.18 \\
\hline
\end{tabular}

Note: (1) Bold values indicated variables having moderate to high loadings on factors (F); F1-3 refers to three independent factors. (2) TN, TP, SC, pH, Q, AP, TW, SR and DO respectively, refer to total nitrogen, total phosphorus, specific conductance, potential of hydrogen, stream flow, atmospheric pressure, water temperature, solar radiation, dissolved oxygen. 
Table A8: Coefficient ( $\beta$ ) of the normalized (dimensionless) PLSR models of stream dissolved oxygen with the dynamic environmental drives after 1000 Monte Carlo simulation of the Gulf Coast water quality monitoring stations.

\begin{tabular}{llllllllllllll}
\hline Stations ID & I & OPC & TN & TP & SC & pH & Q & BP & TW & SR & NSE & RSR \\
\hline USGS-08475000 & TX_1 & 3 & -0.07 & -0.10 & 0.18 & 0.48 & 0.06 & -0.05 & -0.50 & 0.06 & 0.59 & 0.64 \\
USGS-08459200 & TX_2 & 3 & 0.04 & 0.04 & 0.10 & 0.22 & -0.01 & -0.03 & -0.75 & 0.16 & 0.67 & 0.56 \\
USGS-08042554 & TX_3 & 3 & 0.19 & -0.20 & 0.05 & 0.38 & -0.06 & 0.05 & -0.63 & 0.09 & 0.88 & 0.35 \\
USGS-08042546 & TX_4 & 3 & 0.21 & -0.05 & 0.05 & 0.23 & 0.15 & -0.05 & -0.76 & -0.23 & 0.81 & 0.42 \\
USGS-08116650 & TX_5 & 3 & -0.04 & -0.15 & 0.17 & 0.53 & -0.15 & -0.12 & -0.77 & 0.19 & 0.58 & 0.64 \\
USGS-08070200 & TX_6 & 3 & -0.06 & -0.08 & 0.02 & -0.02 & 0.07 & 0.04 & -0.82 & 0.07 & 0.83 & 0.40 \\
USGS-08012150 & LA_1 & 3 & 0.01 & -0.04 & -0.07 & -0.04 & 0.03 & -0.14 & -0.58 & -0.04 & 0.77 & 0.45 \\
USGS-08014500 & LA_2 & 3 & 0.14 & -0.13 & 0.17 & 0.17 & -0.16 & 0.10 & -0.67 & -0.09 & 0.64 & 0.59 \\
USGS-07381590 & LA_3 & 3 & 0.23 & -0.09 & 0.02 & 0.20 & -0.20 & -0.01 & -0.90 & -0.06 & 0.89 & 0.33 \\
USGS-07381495 & LA_4 & 3 & 0.15 & -0.12 & 0.05 & 0.18 & -0.15 & 0.00 & -0.96 & 0.05 & 0.83 & 0.42 \\
USGS-07381600 & LA_5 & 3 & 0.20 & -0.10 & 0.03 & 0.20 & -0.19 & -0.02 & -0.88 & -0.03 & 0.88 & 0.35 \\
USGS-07373420 & LA_6 & 3 & 0.04 & -0.05 & 0.09 & 0.12 & -0.15 & -0.02 & -0.94 & -0.02 & 0.85 & 0.39 \\
USGS-07374000 & LA_7 & 3 & 0.06 & -0.08 & 0.02 & 0.27 & -0.08 & -0.01 & -0.89 & 0.01 & 0.92 & 0.28 \\
USGS-07374525 & LA_8 & 3 & 0.12 & 0.00 & 0.04 & 0.23 & -0.11 & 0.04 & -0.90 & -0.01 & 0.92 & 0.28 \\
USGS-02470500 & AL_1 & 3 & -0.06 & -0.20 & -0.18 & 0.48 & -0.18 & 0.00 & -0.89 & 0.05 & 0.78 & 0.46 \\
USGS-02469762 & AL_2 & 3 & 0.08 & -0.24 & 0.00 & 0.01 & -0.05 & -0.01 & -0.96 & -0.03 & 0.80 & 0.45 \\
USGS-02429500 & AL_3 & 3 & -0.10 & -0.18 & 0.11 & -0.24 & -0.04 & 0.07 & -0.88 & 0.00 & 0.83 & 0.40 \\
*21AWIC-7870 & AL_4 & 3 & 0.01 & 0.10 & -0.04 & 0.29 & 0.01 & -0.09 & -0.82 & -0.06 & 0.94 & 0.25 \\
\hline No:(1) TX, LS, & AL, & ALP &
\end{tabular}

Note: (1) TX, LS, and AL, respectively, refers to stations in Texas, Louisiana, and Alabama. (2) OPC refers to number of optimum partial least square components. (3) NSE refers to Nash-Sutcliffe efficiency. (4) RSR refers to ratio of root-mean-square error to the standard deviation of observations. (5) TN, TP, SC, pH, Q, AP, TW, and SR respectively, refer to total nitrogen, total phosphorus, specific conductance, potential of hydrogen, stream flow, atmospheric pressure, water temperature, and solar radiation. (6) * STORET water quality station. (7) "I" is station identifier. 
Table A8 (continued): Coefficient ( $\beta$ ) of the normalized (dimensionless) PLSR models of stream dissolved oxygen with the environmental drives after 1000 Monte Carlo simulation of the Gulf Coast water quality monitoring station.

\begin{tabular}{lllllllllllll}
\hline Stations ID & I & OPC & TN & TP & SC & pH & Q & BP & TW & SR & NSE & RSR \\
\hline USGS-02359170 & FL_1 & 3 & 0.11 & -0.18 & 0.09 & -0.08 & -0.09 & -0.03 & -0.62 & -0.12 & 0.60 & 0.62 \\
USGS-02312600 & FL_2 & 3 & -0.21 & -0.42 & -0.03 & -0.25 & 0.06 & 0.08 & -0.46 & -0.29 & 0.86 & 0.36 \\
USGS-02312500 & FL_3 & 3 & -0.28 & -0.09 & 0.24 & 0.18 & 0.03 & 0.02 & -0.46 & -0.15 & 0.84 & 0.39 \\
USGS-02310947 & FL_4 & 3 & -0.15 & 0.01 & -0.54 & 0.06 & 0.16 & 0.15 & -0.18 & 0.06 & 0.68 & 0.53 \\
USGS-02301300 & FL_5 & 3 & -0.11 & -0.09 & 0.20 & 0.20 & -0.58 & -0.06 & -0.49 & 0.05 & 0.92 & 0.28 \\
USGS-02303000 & FL_6 & 3 & 0.08 & -0.11 & 0.23 & 0.08 & -0.03 & 0.20 & -0.46 & -0.08 & 0.91 & 0.29 \\
USGS-02309445 & FL_7 & 4 & -0.20 & -0.35 & -0.08 & -0.02 & 0.19 & -0.15 & -0.75 & 0.20 & 0.73 & 0.50 \\
USGS-02309425 & FL_8 & 3 & -0.06 & -0.18 & 0.27 & -0.17 & 0.18 & -0.01 & -0.62 & -0.03 & 0.67 & 0.55 \\
USGS-02307671 & FL_9 & 3 & -0.07 & -0.27 & -0.14 & 0.13 & 0.38 & 0.01 & -0.61 & 0.00 & 0.71 & 0.52 \\
USGS-02307731 & FL_10 & 3 & 0.10 & -0.23 & -0.09 & -0.07 & 0.20 & 0.14 & -0.76 & 0.18 & 0.78 & 0.45 \\
USGS-02310300 & FL_11 & 3 & 0.11 & -0.13 & -0.33 & -0.08 & 0.27 & 0.05 & -0.30 & -0.07 & 0.92 & 0.26 \\
USGS-02300100 & FL_12 & 3 & -0.01 & -0.05 & 0.08 & -0.02 & -0.33 & -0.07 & -0.75 & 0.01 & 0.80 & 0.42 \\
USGS-02295420 & FL_13 & 3 & -0.18 & -0.01 & 0.00 & -0.06 & -0.11 & 0.08 & -0.77 & -0.03 & 0.84 & 0.39 \\
USGS-02296750 & FL_14 & 4 & -0.37 & 0.06 & 0.27 & 0.16 & -0.03 & -0.06 & -0.74 & -0.26 & 0.76 & 0.48 \\
USGS-02298123 & FL_15 & 3 & -0.04 & -0.30 & -0.06 & -0.18 & -0.32 & -0.03 & -0.62 & -0.03 & 0.89 & 0.32 \\
*WQX-10MIGR10 & FL_16 & 3 & 0.18 & -0.05 & -0.49 & 0.26 & 0.17 & 0.14 & -0.62 & -0.02 & 0.86 & 0.37 \\
*WQX-10MIGR80 & FL_17 & 3 & -0.29 & -0.21 & 0.09 & 0.46 & -0.01 & 0.22 & -0.24 & 0.01 & 0.80 & 0.44 \\
*WQX-46B-9GR & FL_18 & 3 & 0.10 & 0.09 & 0.19 & 0.74 & 0.02 & -0.23 & -0.29 & 0.06 & 0.65 & 0.58 \\
\hline NE(1) FLFf & & &
\end{tabular}

Note: (1) FL refers stations in Florida. (2) OPC refers to number of optimum partial least square components. (3) NSE refers to Nash-Sutcliffe efficiency. (4) RSR refers to ratio of root-mean-square error to the standard deviation of observations. (5) TN, TP, SC, pH, Q, AP, TW, and SR respectively, refer to total nitrogen, total phosphorus, specific conductance, potential of hydrogen, stream flow, atmospheric pressure, water temperature, and solar radiation. (6) * 21FLEECO. (7) "I" is station identifier. 


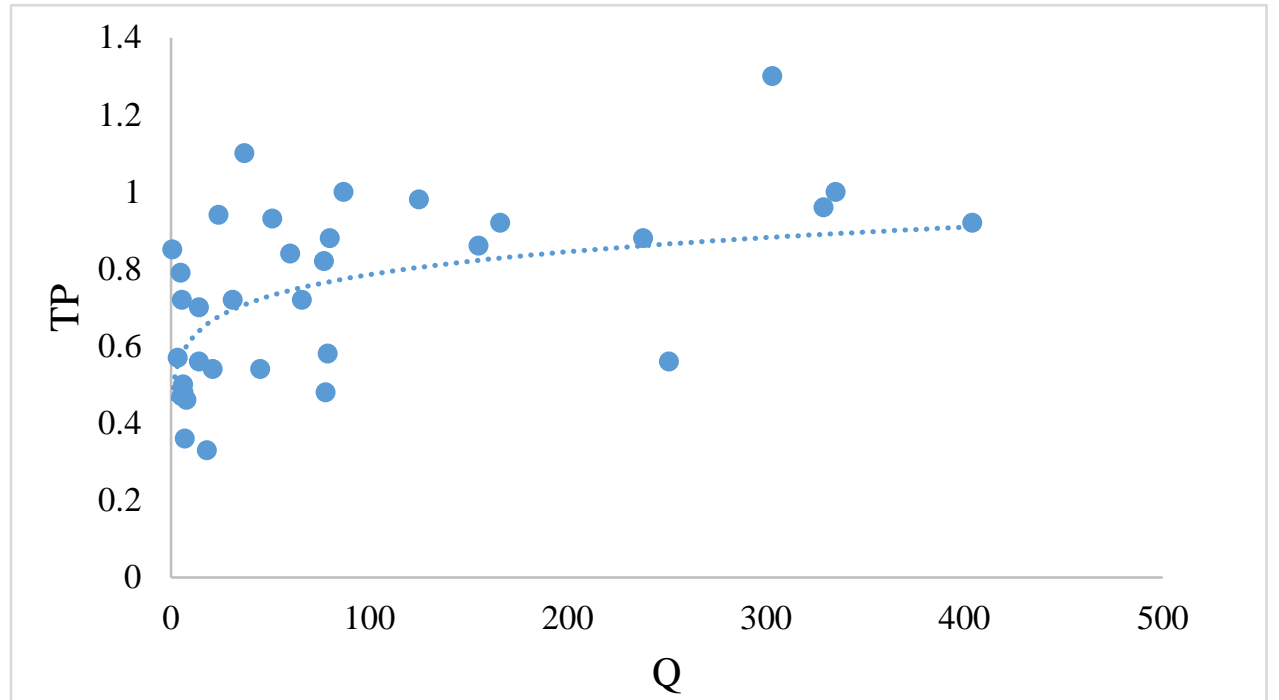

Figure A1: Scatter plot of flow rate $\left(\mathrm{Q}, \mathrm{ft}^{3} / \mathrm{s}\right)$ with total phosphorus $(\mathrm{TP}, \mathrm{mg} / \mathrm{L})$. 

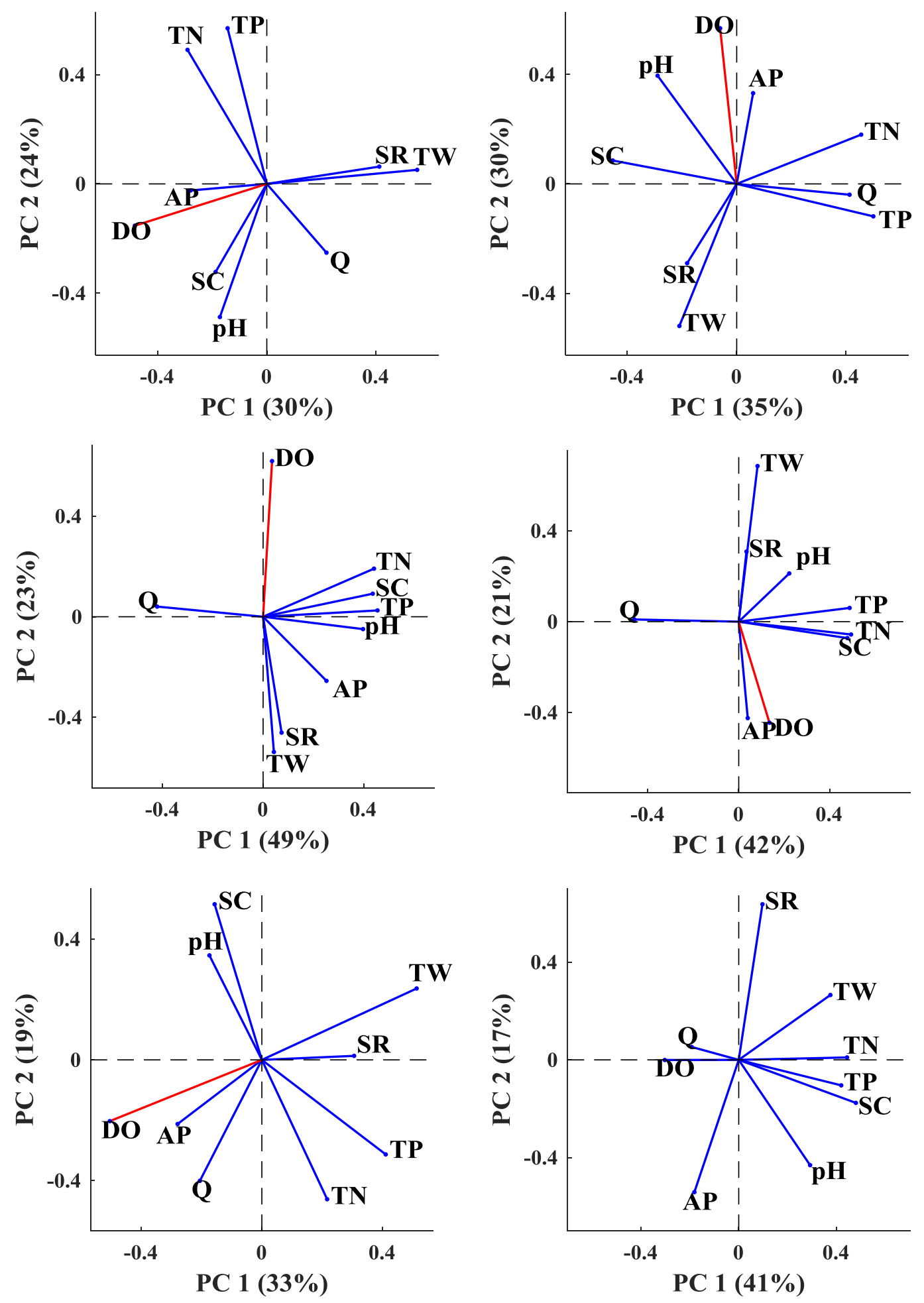

Figure A2: Biplot of TW dominated regime obtained from principal component analysis showing interrelation of DO with dynamic environmental driver. 

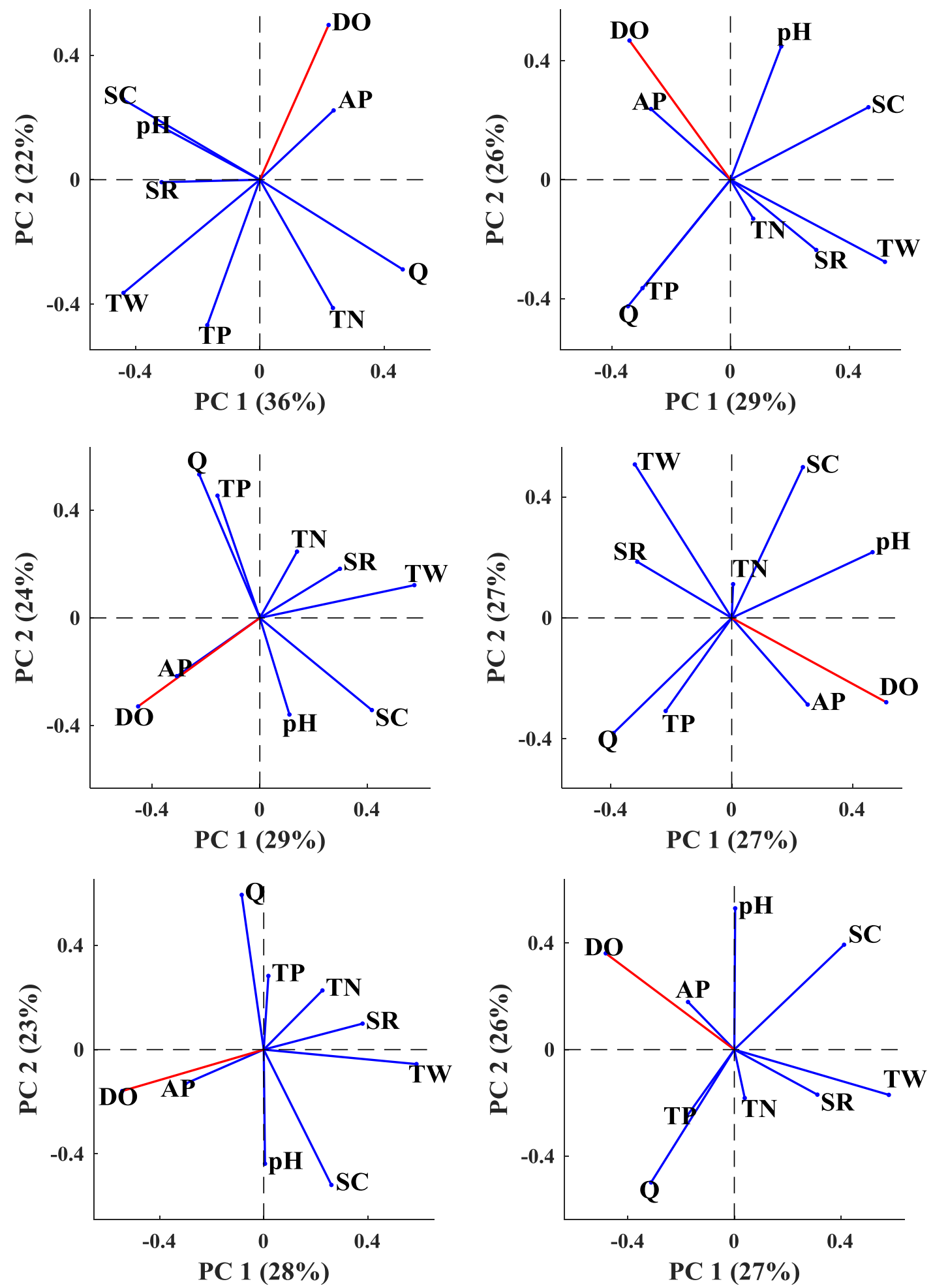

Figure A2 (continued): Biplot of TW dominated regime obtained from principal component analysis showing interrelation of DO with dynamic environmental driver. 

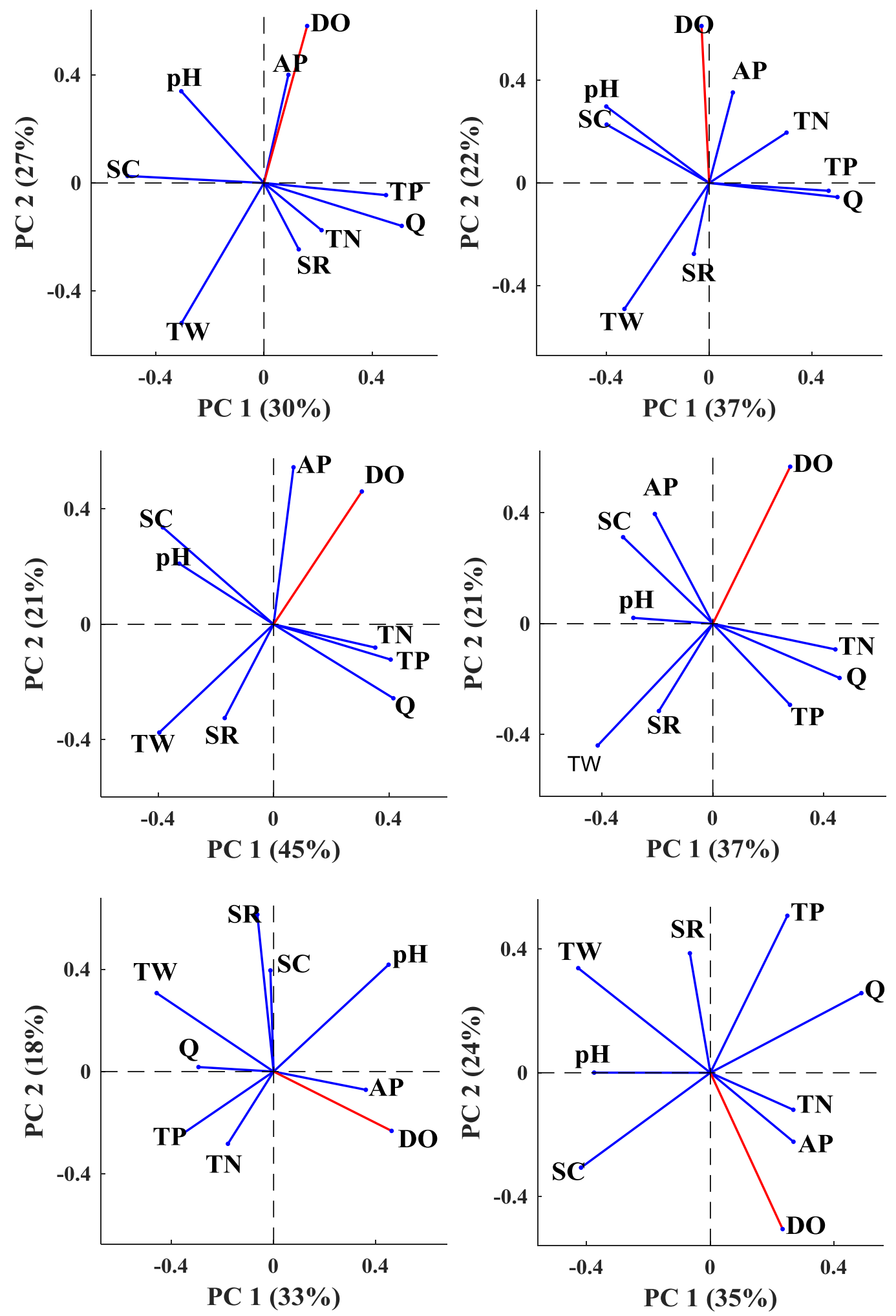

Figure A2 (continued): Biplot of TW dominated regime obtained from principal component analysis showing interrelation of DO with dynamic environmental driver. 

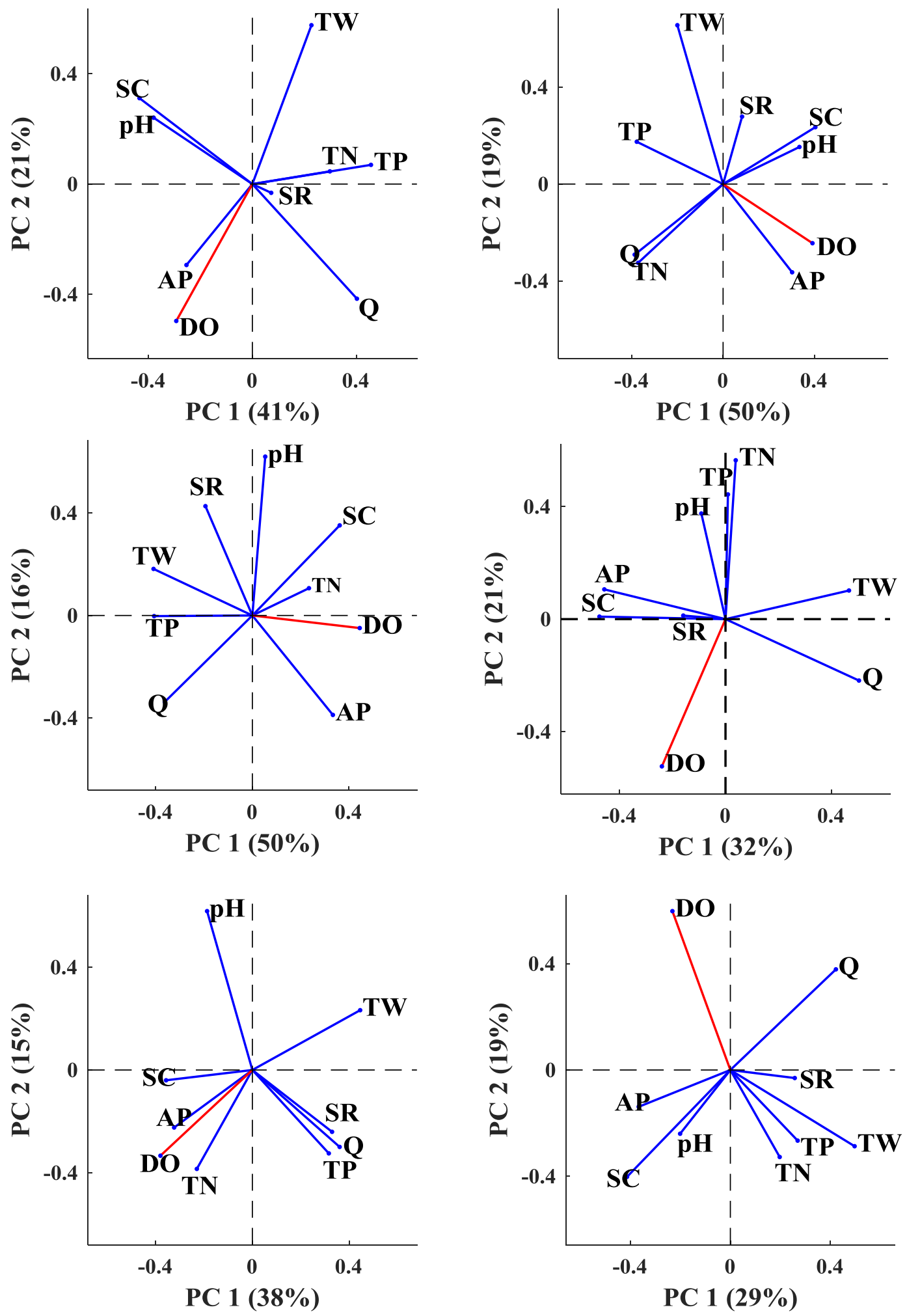

Figure A2 (continued): Biplot of TW dominated regime obtained from principal component analysis showing interrelation of DO with dynamic environmental driver. 

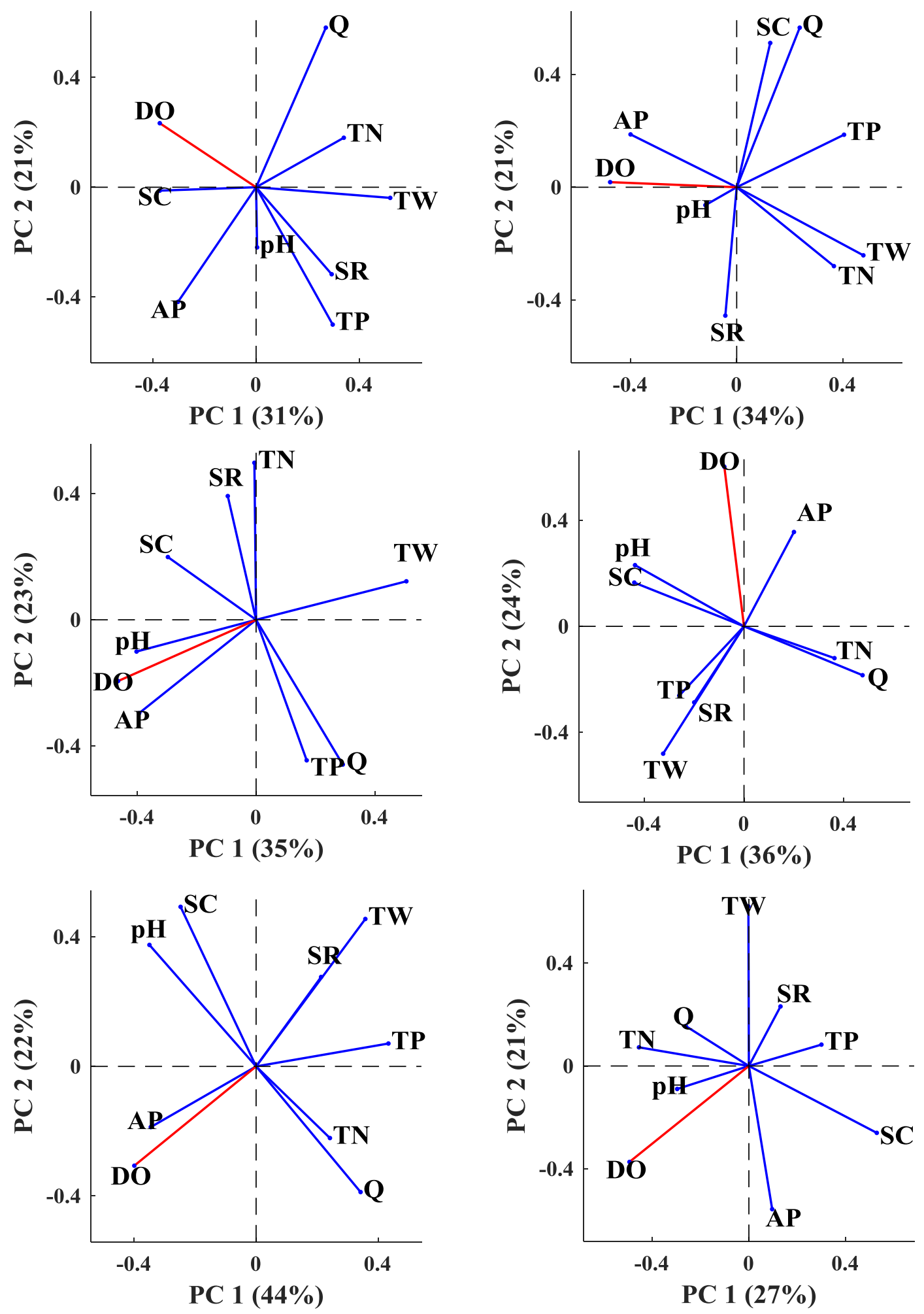

Figure A2 (continued): Biplot of TW dominated regime obtained from principal component analysis showing interrelation of DO with dynamic environmental driver. 


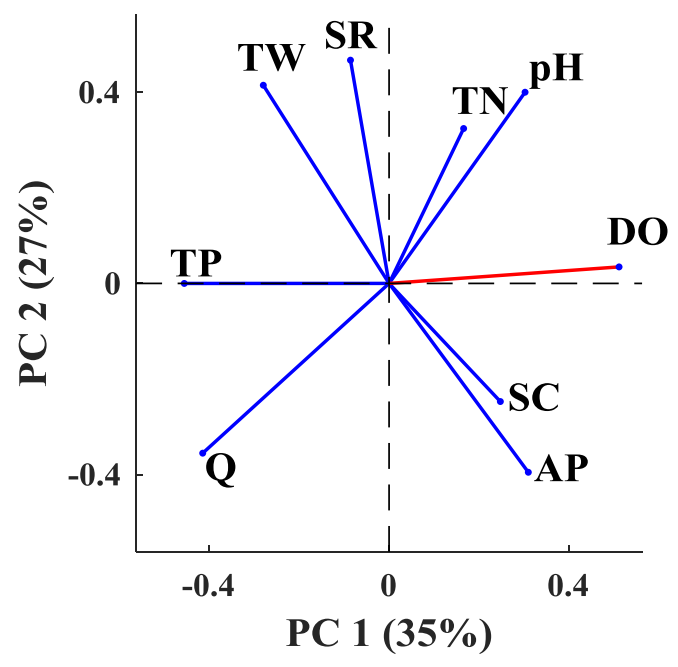

Figure A3: Biplot of Q dominated regime obtained from principal component analysis showing interrelation of DO with the dynamic environmental drivers.
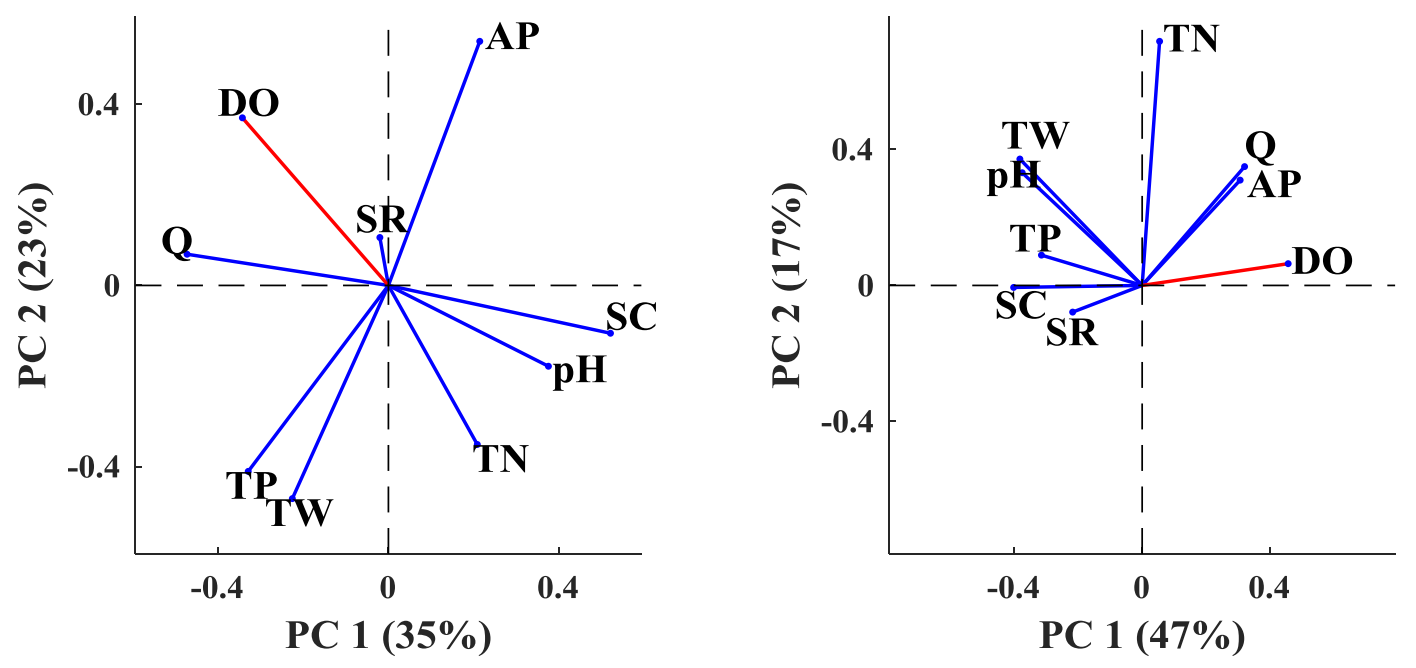

Figure A4: Biplot of SC dominated regime obtained from principal component analysis showing interrelation of DO with the dynamic environmental drivers. 

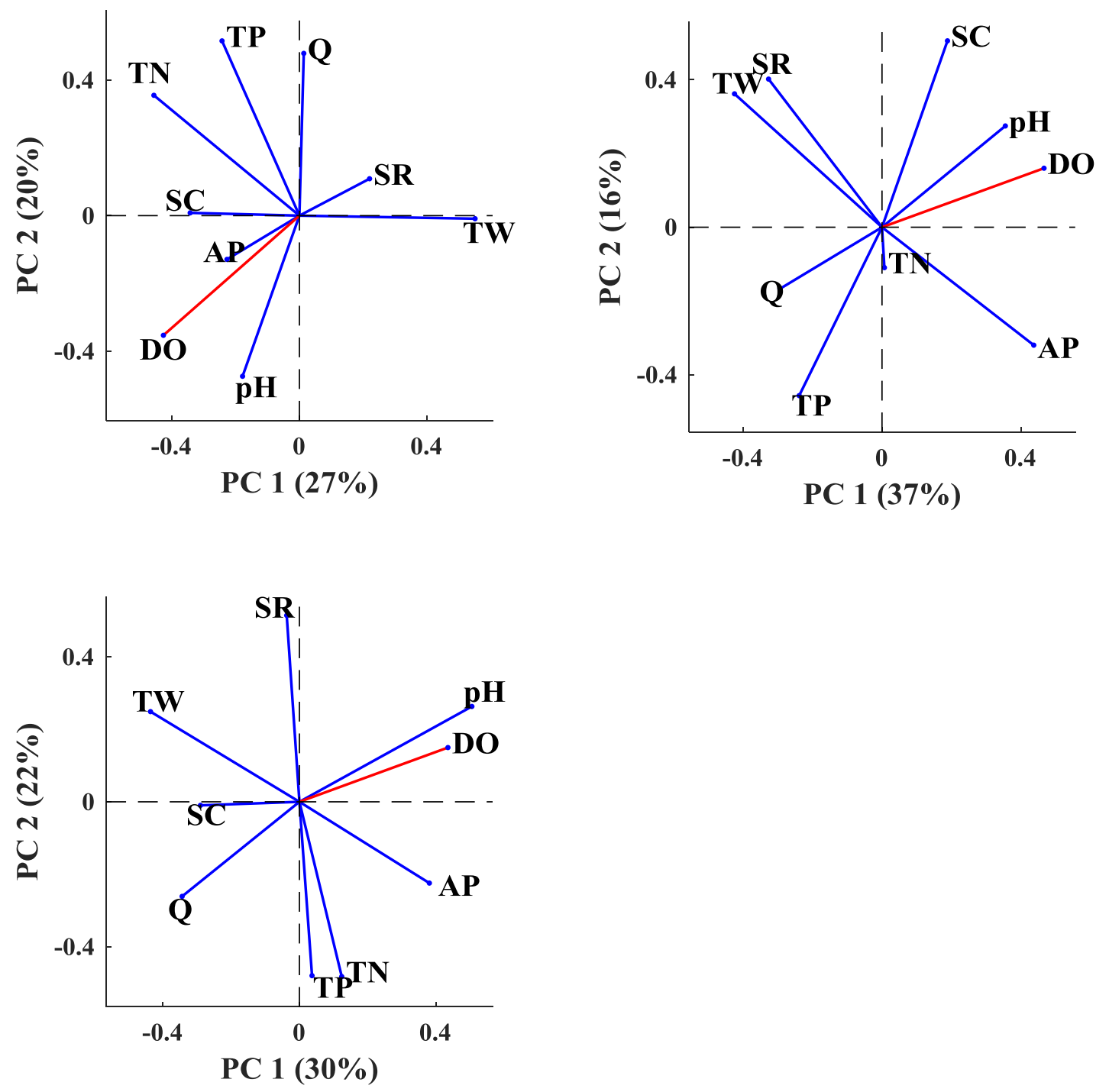

Figure A5: Biplot of $\mathrm{pH}$ dominated regime obtained from principal component analysis showing interrelation of DO with the dynamic environmental drivers. 
(a)

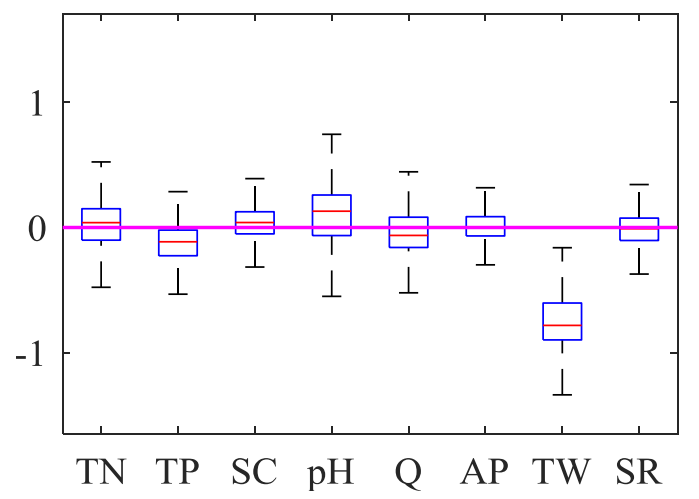

(c)

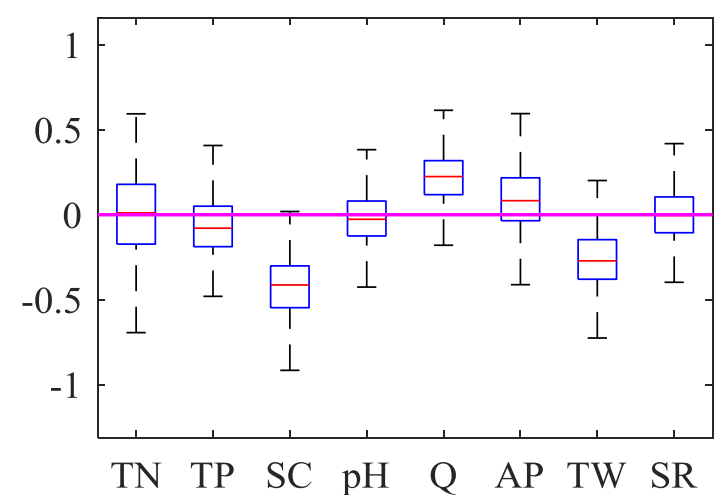

(b)

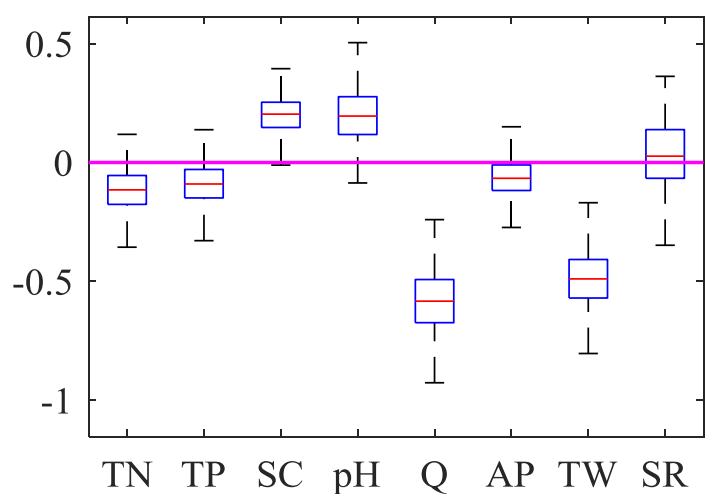

(d)

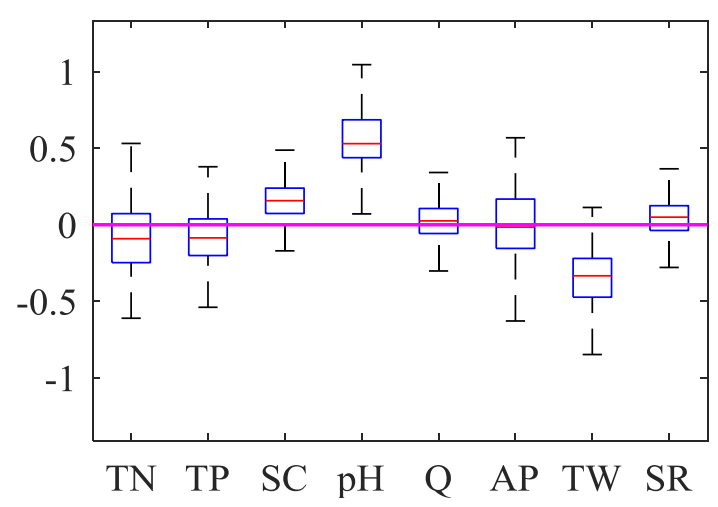

Figure A6: Box plot of Beta coefficient after 1000 Monte Carlo for each environmental regime: (a) TW dominated regime, (b) $\mathrm{Q}$ dominated regime, (c) $\mathrm{SC}$ dominated regime, and (d) $\mathrm{pH}$ dominated regime. The magenta color shows the zero-zero line. 


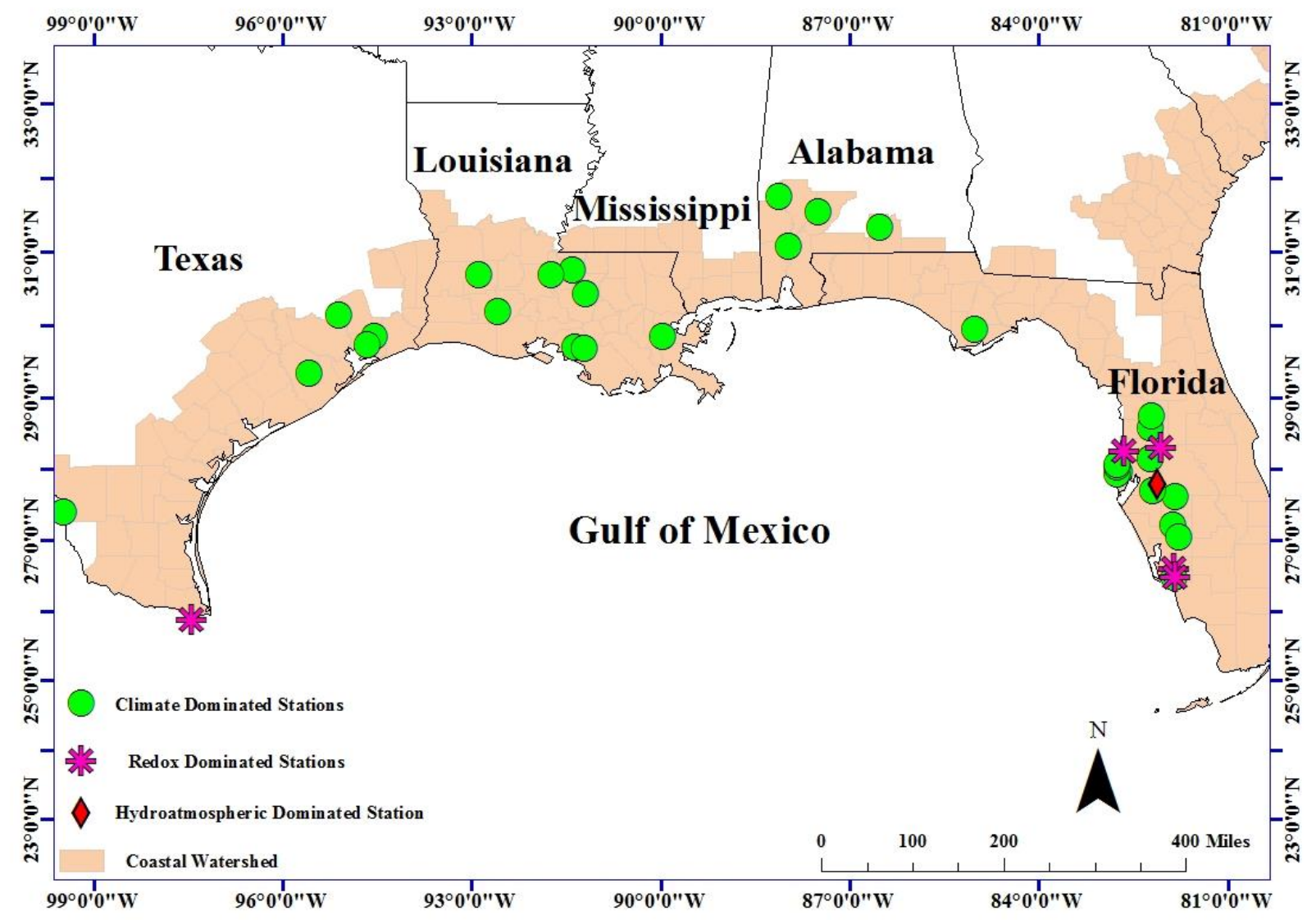

Figure A7: Map of the study area and the dominant process components for each station. 


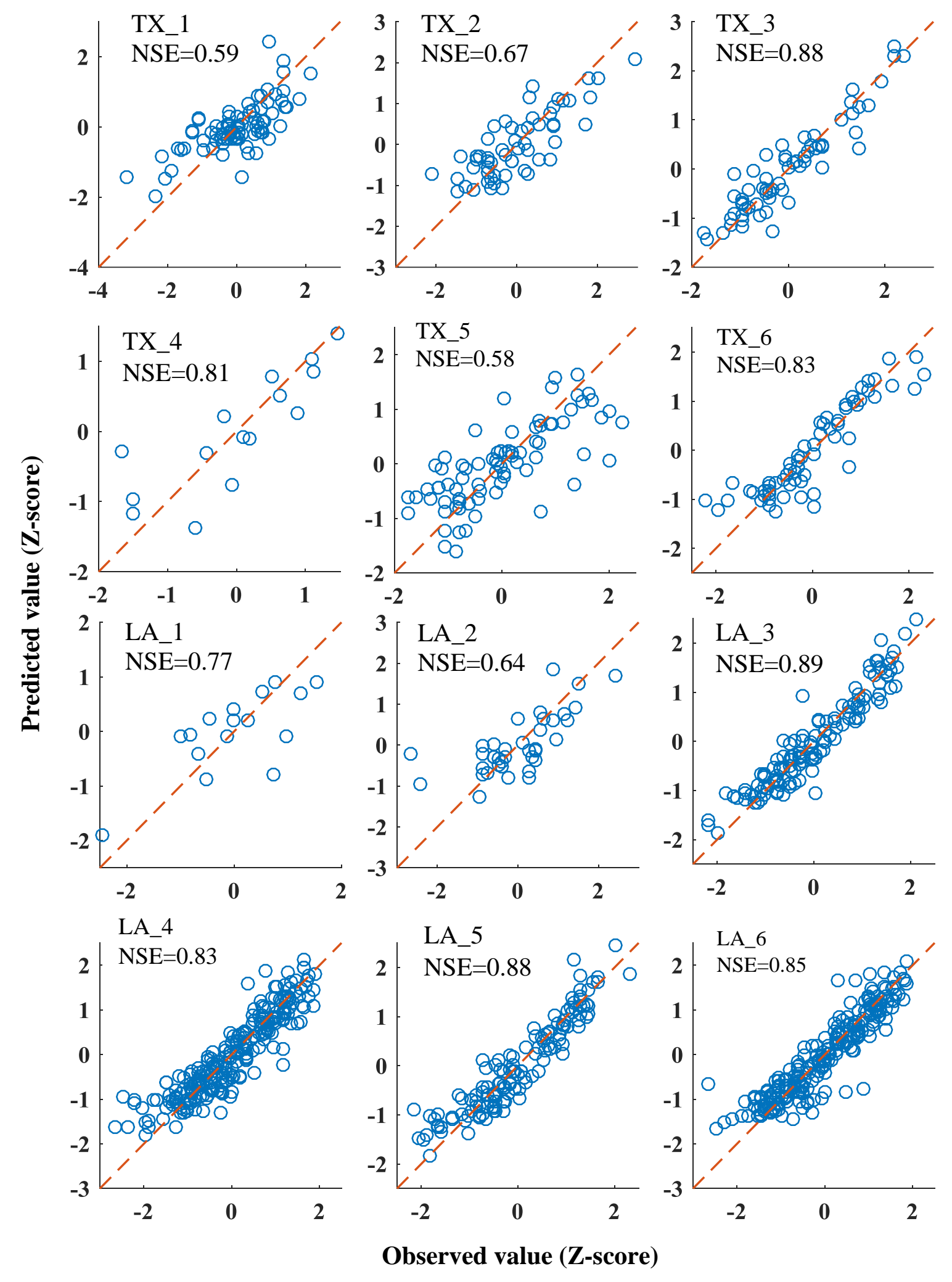

Figure A8: Observed vs. predicted Z-score of dissolved oxygen. 

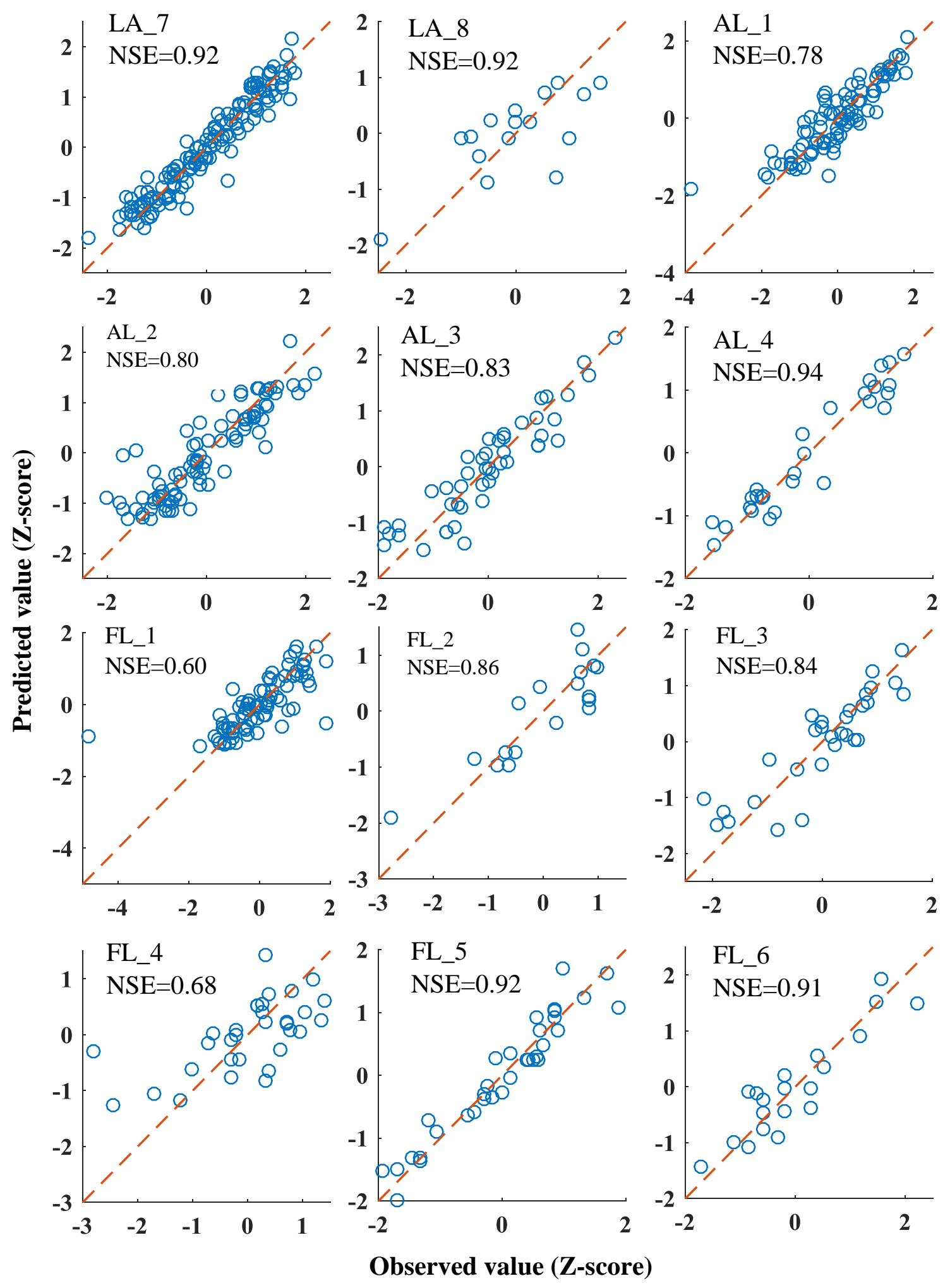

Figure A8 (continued): Observed vs. predicted Z-score of dissolved oxygen. 

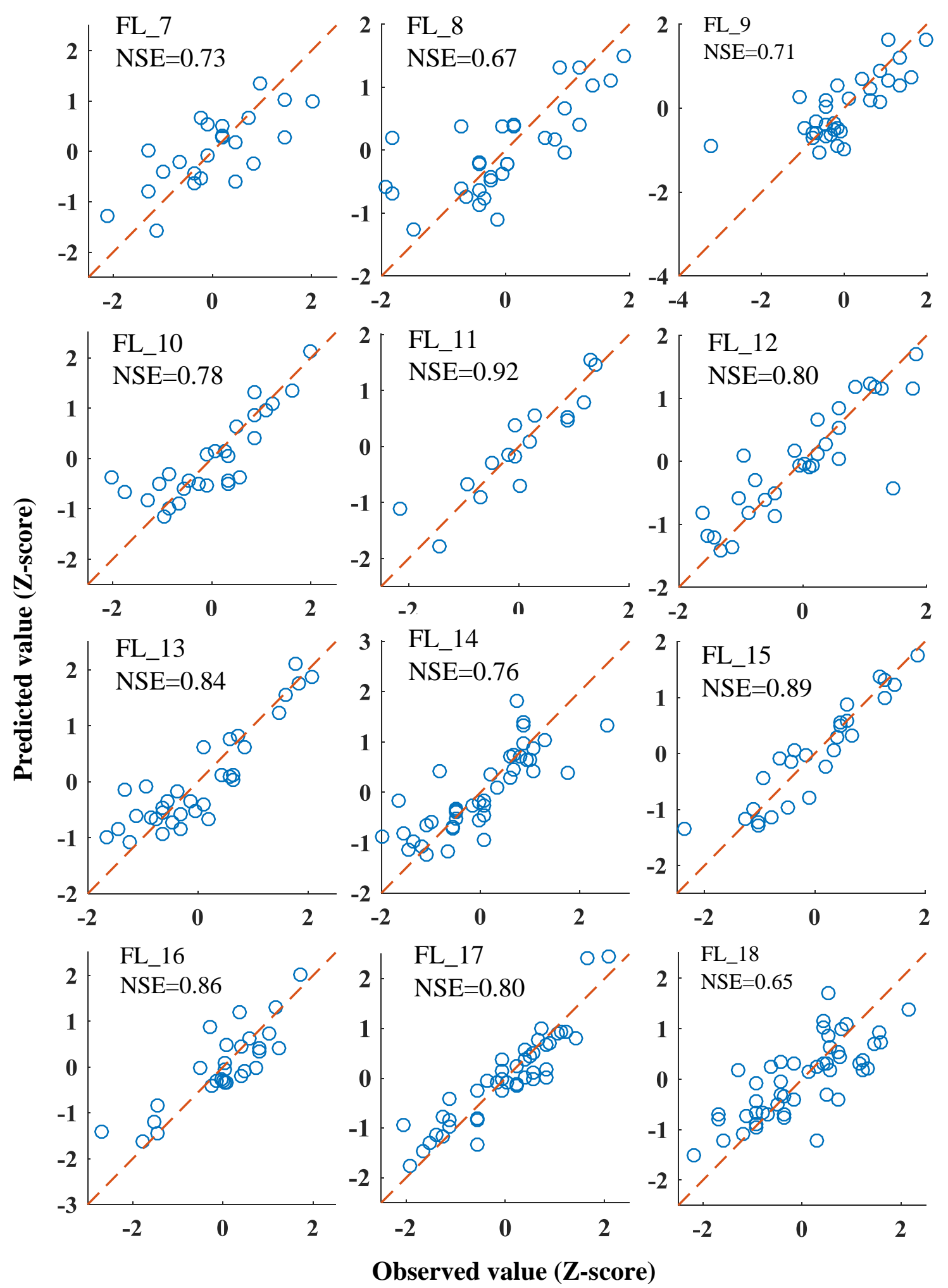

Figure A8 (continued): Observed vs. predicted Z-score of dissolved oxygen. 